\title{
Options Study - Phase II
}

R. Wigeland

T. Taiwo

M. Todosow

W. Halsey

J. Gehin

September 2010

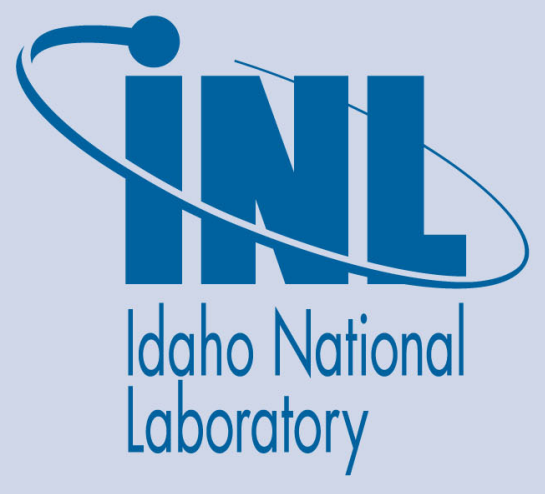

The INL is a U.S. Department of Energy National Laboratory operated by Battelle Energy Alliance 
INL/EXT-10-20439

FCRD-TIO-2010-000167

\section{Options Study - Phase II}

${ }^{1}$ ANL

${ }^{2} \mathrm{BNL}$

${ }^{3}$ LLNL

${ }^{4}$ ORNL
R. Wigeland

T. Taiwo ${ }^{1}$

M. Todosow ${ }^{2}$

W. Halsey ${ }^{3}$

J. Gehin ${ }^{4}$

September 2010

Idaho National Laboratory

Fuel Cycle Research \& Development

Technical Integration Office

Idaho Falls, Idaho 83415

http://www.inl.gov

Prepared for the

U.S. Department of Energy

Office of Nuclear Energy

Under DOE Idaho Operations Office

Contract DE-AC07-05ID14517 


\section{DISCLAIMER}

This information was prepared as an account of work sponsored by an agency of the U.S. Government. Neither the U.S. Government nor any agency thereof, nor any of their employees, makes any warranty, expressed or implied, or assumes any legal liability or responsibility for the accuracy, completeness, or usefulness, of any information, apparatus, product, or process disclosed, or represents that its use would not infringe privately owned rights. References herein to any specific commercial product, process, or service by trade name, trade mark, manufacturer, or otherwise, does not necessarily constitute or imply its endorsement, recommendation, or favoring by the U.S. Government or any agency thereof. The views and opinions of authors expressed herein do not necessarily state or reflect those of the U.S. Government or any agency thereof. 


\section{SUMMARY}

The Options Study has been conducted for the purpose of evaluating the potential of alternative integrated nuclear fuel cycle options to favorably address the issues associated with a continuing or expanding use of nuclear power in the United States. The study produced information that can be used to inform decisions identifying potential directions for research and development on such fuel cycle options. An integrated nuclear fuel cycle option is defined in this study as including all aspects of the entire nuclear fuel cycle, from obtaining natural resources for fuel to the ultimate disposal of used nuclear fuel (UNF) or radioactive wastes. Issues such as nuclear waste management, especially the increasing inventory of used nuclear fuel, the current uncertainty about used fuel disposal, and the risk of nuclear weapons proliferation have contributed to the reluctance to expand the use of nuclear power, even though it is recognized that nuclear power is a safe and reliable method of producing electricity. In this Options Study, current, evolutionary, and revolutionary nuclear energy options were all considered, including the use of uranium and thorium, and both once-through and recycle approaches. Available information has been collected and reviewed in order to evaluate the ability of an option to clearly address the challenges associated with the current implementation and potential expansion of commercial nuclear power in the United States. This Options Study is a comprehensive consideration and review of fuel cycle and technology options, including those for disposal, and is not constrained by any limitations that may be imposed by economics, technical maturity, past policy, or speculated future conditions. This Phase II report is intended to be used in conjunction with the Phase I report, and much information in that report is not repeated here, although some information has been updated to reflect recent developments.

The focus in this Options Study was to identify any nuclear fuel cycle technology or option that may result in a significant beneficial impact to the issues as compared to the current U.S. approach of oncethrough use of nuclear fuel in LWRs or similar reactors followed by direct disposal of UNF. This approach was taken because incremental differences may be difficult to clearly identify and justify due to the large uncertainties that can be associated with the specific causes of the issues. Phase II of this Options Study continued the review of nuclear fuel cycle options that was initiated and documented during Phase I, concentrating on reviewing and summarizing the potential of integrated nuclear fuel cycles. However, based on the reviews of previous studies and available data, it was not always possible to clearly determine sufficiently large differences between the various fuel cycle and technology options for some of the issues or evaluation measures, for example, in cases where only incremental differences with respect to the issues might be achieved regardless of the fuel cycle option or technologies being considered, or where differences were insufficient to clearly rise above the uncertainties. In this Options Study, "significant benefits" were defined as those resulting in an improvement that is clearly greater than the uncertainties, typically an order of magnitude or greater improvement in most of the evaluation measures. However, it is recognized that smaller improvements can also be "significant" depending on the context, such as for costs, but that these may be difficult to acknowledge depending on the size of the uncertainties.

In this Phase II report, the issues with nuclear power are grouped into five categories. For each of the issues, the fundamental nature of the issue and the resulting requirements for a fuel cycle to be able to beneficially address the issue are summarized. All fuel cycles are then reviewed, highlighting those issues that are amenable to improvement by using an advanced fuel cycle, and identifying the fuel cycle options that in principle should be able to have a significant beneficial impact on the issues.

Depending on which issue or issues are of highest importance, this information can be used to inform decisions about productive directions for R\&D. The recently-issued DOE roadmap had 4 top level R\&D Objectives, as follows:

1. Develop technologies and other solutions that can improve the reliability, sustain the safety, and extend the life of current reactors 
2. Develop improvements in the affordability of new reactors to enable nuclear energy to help meet the administration's energy security and climate change goals

3. Develop sustainable nuclear fuel cycles

4. Understand and minimize the risks of nuclear proliferation and terrorism

The summary observations from this Options Study provide information on what issues associated with nuclear power are addressable with a nuclear fuel cycle option, and the extent to which the issues can be affected, especially for R\&D Objectives 3 and 4. A summary of the observations from the Options Study is provided in the following table.

\begin{tabular}{|c|c|c|}
\hline Nuclear Power Issue & $\begin{array}{l}\text { Nuclear Fuel Cycle Option Requirements to } \\
\text { Provide Significant Benefits }\end{array}$ & $\begin{array}{l}\text { Suitable Nuclear Fuel Cycle } \\
\text { Options }\end{array}$ \\
\hline Nuclear Waste Management & $\begin{array}{l}\text { - Reduce actinide and decay product content in } \\
\text { UNF and wastes requiring geologic disposal: } \\
\text { - Complete consumption of fuel } \\
\text { - Actinide recycle } \\
\text { - Reduce decay heat of UNF and wastes for } \\
\text { disposal in some geologic environments. } \\
\text { - Limit LLW generation. }\end{array}$ & $\begin{array}{l}\text { - Recycle options with } \\
\text { actinide recycle and no UNF } \\
\text { disposal. } \\
\text { - Externally-driven once- } \\
\text { through with complete fuel } \\
\text { consumption. }\end{array}$ \\
\hline Proliferation Risk and Security & $\begin{array}{l}\text { - Fuel cycles and technologies that enable } \\
\text { effective and efficient safeguards } \\
\text { implementation, including: } \\
\text { - Use of existing safeguards technologies } \\
\text { - Best practices } \\
\text { - Fuel cycles that allow effective security and } \\
\text { materials with lower attractiveness. }\end{array}$ & $\begin{array}{l}\text { - All fuel cycle options using } \\
\text { "safeguards-friendly" } \\
\text { technologies. } \\
\text { - Fuel cycles with lower } \\
\text { material attractiveness for } \\
\text { SNM in UNF and products. }\end{array}$ \\
\hline Safety & $\begin{array}{l}\text { - Use technologies with no irresolvable safety } \\
\text { vulnerabilities. }\end{array}$ & $\begin{array}{l}\text { - Virtually all fuel cycle } \\
\text { options and technologies. }\end{array}$ \\
\hline Sustainability & $\begin{array}{l}\text { - Increase internal conversion of fertile materials } \\
\text { to fissile materials, i.e. "breeding" to improve } \\
\text { fuel utilization and reduce environmental impact. } \\
\text { - Reduce decay heat of UNF and wastes going to } \\
\text { deep geologic disposal to reduce repository space } \\
\text { requirements. }\end{array}$ & $\begin{array}{l}\text { - Once-through and recycle } \\
\text { fuel cycles with more } \\
\text { efficient breeding than } \\
\text { LWRs. } \\
\text { - Recycle fuel cycles with } \\
\text { actinide recycle and no UNF } \\
\text { disposal. }\end{array}$ \\
\hline Economics & $\begin{array}{l}\text { - Avoid unnecessary increases in complexity. } \\
\text { - Avoid systems with larger waste generation, } \\
\text { extreme technical requirements or inherent safety } \\
\text { or security vulnerabilities requiring additional } \\
\text { design features, or requiring rare resources. }\end{array}$ & $\begin{array}{l}\text { - All fuel cycle options but } \\
\text { less complex technologies } \\
\text { may have fewer issues with } \\
\text { costs. }\end{array}$ \\
\hline
\end{tabular}

With respect to the R\&D Objectives, it appears that nuclear waste management may only be significantly improved with nuclear fuel cycle options using recycle, since processing can be used to reduce the radiological risk of UNF by recycling hazardous materials, and to improve the characteristics of wastes requiring deep geologic disposal, providing for more efficient use of deep geologic disposal facilities and enabling other deep geologic disposal options. Once-through fuel cycle options are limited in this respect since disposal of UNF is always required, although one exception may be the use of externally-driven irradiation systems to achieve essentially complete consumption of the fuel.

It is clear that alternative nuclear fuel cycles can contribute to "developing sustainable nuclear fuel cycles" by increasing the utilization of fuel resources, which reduces the environmental impact related to obtaining the fuel resource and increases self-sufficiency of the fuel resources. Results of the reviews performed in the Options Study show that while this is possible to some extent with a few once-through 
fuel cycle options using externally-driven irradiation systems, recycle options can develop this potential to a much greater extent, and for a wider range of technology options.

For the other issues, proliferation risk and security, safety, and economics, the effects of using alternative nuclear fuel cycles were not so clearly distinguishable. The reviews indicated:

- While alternative nuclear fuel cycles and technologies may not have any significant difference in proliferation risk based on the technical aspects related to the materials and products, some options may assist in reducing the risks from proliferation and terrorism by using fuel cycles and technologies that allow effective and efficient implementation of nuclear safeguards, by enabling security at nuclear fuel cycle facilities, by reducing the attractiveness of readily-available materials, and by using fuel cycles and technologies that would not contribute to knowledge transfers of sensitive technologies.

- There did not seem to be any discrimination in the level of safety that resulted from the choice of the fuel cycle option since all fuel cycle facilities including reactors are strictly licensed and regulated for safety. However, it was also noted that some technologies had additional safety-related risks that would require more design features for prevention and mitigation measures, where achieving the required level of safety may have negative economic impacts.

- From an economics point of view, review of previous studies and estimates resulted in the observation that the overall economics for an alternative fuel cycle did not appear to result in a change that was clearly larger than the uncertainties, i.e., even though there were differences in the estimated mean cost for various fuel cycle options, these differences were well within the overlapping uncertainty distributions for each of the estimates. As a result, it was observed that alternative fuel cycles may be considered without necessarily incurring significantly different overall costs. However, the same is not true for the technologies, where the complexity of the technology may be a significant contributor to the costs.

It should be noted for these three issues that although it was not possible to clearly identify fuel cycle options that could provide a significant benefit for a variety of reasons; proliferation risk and security (high level of subjectivity), safety (regulation requires all systems to be safe), and economics (uncertainties are larger than the differences), this is not necessarily a negative result since the lack of distinction between fuel cycle options on these issues may be contrary to prevailing perceptions. These observations allow consideration of all fuel cycle options on a more or less equal basis with respect to these issues, enabling a wide range of nuclear fuel cycle options.

Overall, this Options Study has reviewed numerous past studies on nuclear fuel cycles, specific fuel cycle approaches, and individual aspects of the fuel cycle, with the purpose of evaluating the capabilities of nuclear fuel cycle options to significantly benefit the current issues with nuclear power. The issues have been analyzed to provide the underlying reasons for the issues and to develop requirements for an alternative fuel cycle. For each issue, the broad range of specific fuel cycle options are considered in the context of the nuclear power issues to identify whether significantly beneficial approaches fundamentally exist, and if so, what they are. Issues where no options apparently exist for significant beneficial improvement are also discussed, providing the reasons why options do not appear to exist. For those issues that can have significant beneficial improvement, examples of existing or proposed options are provided for perspective on the extent to which technologies may be available to address the issues, and where additional $\mathrm{R} \& \mathrm{D}$ would be required.

Some of the nuclear fuel cycle options and technologies are more well-developed, having been the subject of research for several decades in some cases, since the issues with nuclear power are decades old, with changing emphasis on each issue over time. Other possibilities are quite immature, and would require substantial investment in time and funding (and in some cases a number of revolutionary technical 
developments) to bring them to a level of maturity sufficient to evaluate their suitability for further development and potential implementation. Consequently, the R\&D effort and duration cover a wide range of possibilities. Since the goals for each issue associated with nuclear power can be accomplished with numerous specific technology solutions for a given fuel cycle option in many cases, it would appear that the selected technologies from the set of specific technology options may be more a matter of preference rather than one of fundamental technical difference. However, within a given fuel cycle option, technology choices for each part of the fuel cycle may not be independent of one another, such as the implications of the intended environment for deep geologic disposal on the recycle requirements. Once decisions have been made as to the issues that are to be addressed with the fuel cycle option, the time required for development and commercial deployment may also cover a wide range, where more mature technologies can be implemented more quickly, perhaps within a decade or two, while immature technologies accomplishing the same goals would require more time, at least several decades.

As a result, the required $R \& D$ to address one or more of the issues associated with nuclear power by using a nuclear fuel cycle option also covers a wide range. Technology solutions that are barely at the stage of proof-of-principle would require substantial $R \& D$ and perhaps even fundamental breakthroughs, while those that are at the pilot-scale demonstration phase would need less R\&D, although interestingly not necessarily less funding since demonstration facilities can be expensive. Given the range of potential nuclear fuel cycle solutions for each issue, the range of technology solutions, and the implications for $\mathrm{R} \& \mathrm{D}$, it would seem that decisions would first need to be made on what the nuclear fuel cycle option would be asked to do. Next, any external constraints, including policy decisions, would need to be established that could restrict the range of available fuel cycle or technology options, recognizing that some policy decisions may have the ability to eliminate any possibility of addressing one or more issues. This Options Study provides an overview of what is possible and what may not be possible, along with cautions about the level of subjectivity that exists for some of the issues.

Moving forward, more detailed examination of those options that have the potential to address the issues with nuclear power appears warranted. It is quite clear that the approach taken in this Options Study of considering the entire nuclear fuel cycle as an integrated entity is absolutely essential for developing an effective integrated nuclear fuel cycle option that considers all aspects of the nuclear fuel cycle, from mining to energy production to disposal, since many of the aspects of each activity are so closely interrelated and affect the issues with nuclear power. 


\section{CONTENTS}

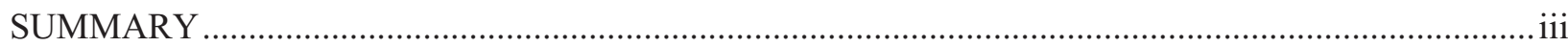

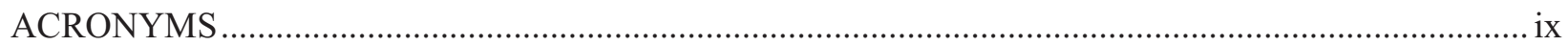

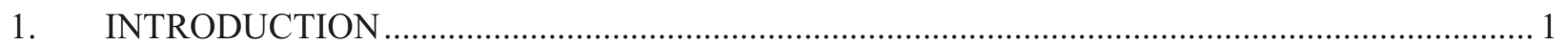

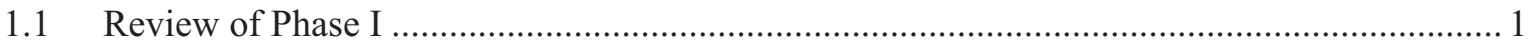

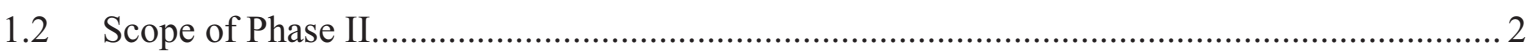

2. ADDRESSING THE ISSUES WITH NUCLEAR POWER ........................................................... 3

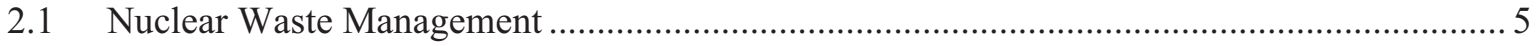

2.1.1 Fuel Cycle Resource Needs for Waste Disposal ......................................................... 5

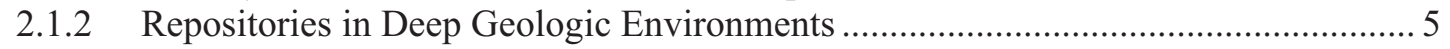

2.1.3 Near-Surface Disposal Environment Characteristics - LLW .................................... 10

2.1.4 Technical Implications for a Nuclear Fuel Cycle Option ......................................... 11

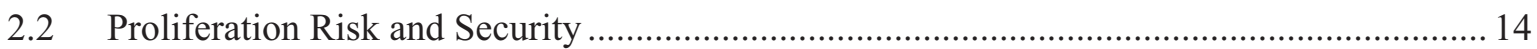

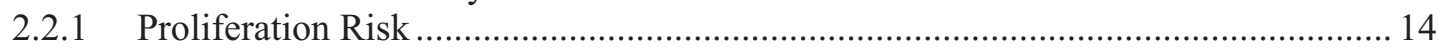

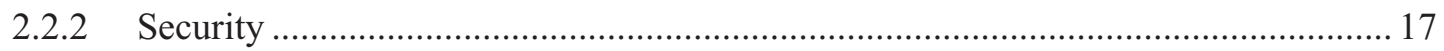

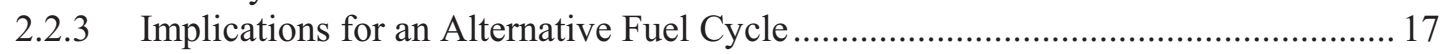

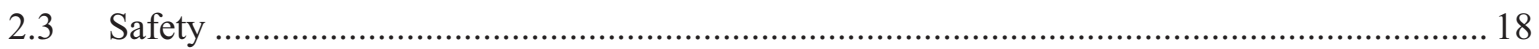

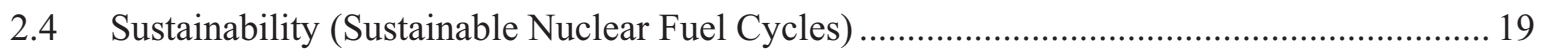

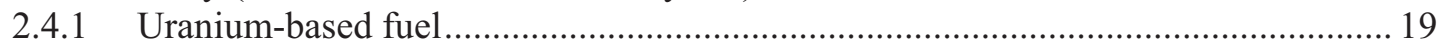

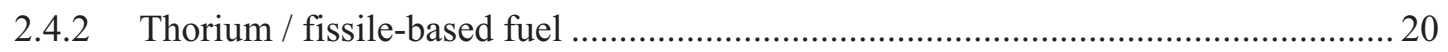

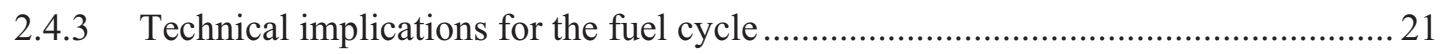

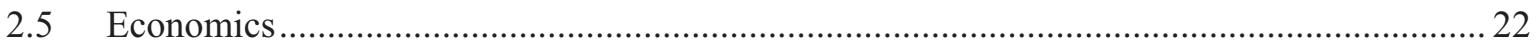

2.5.1 Uncertainties in the Cost of Nuclear Facilities ........................................................ 22

2.5.2 Uncertainties in the Cost of Nuclear Fuel Cycles .....................................................2

2.5.3 Economics Implications for the Fuel Cycle ....................................................... 25

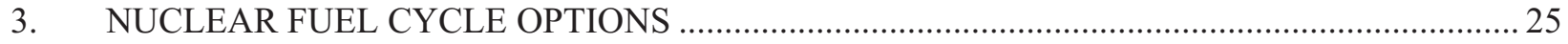

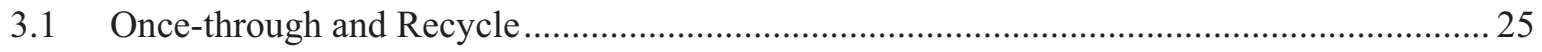

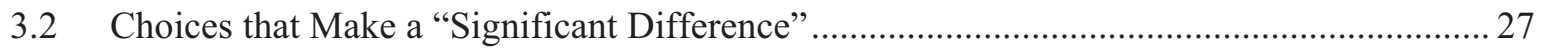

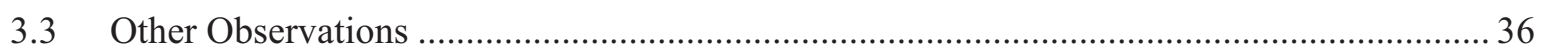

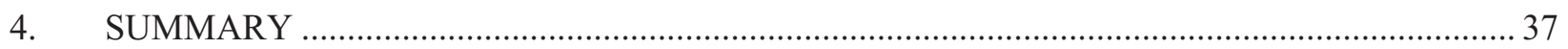

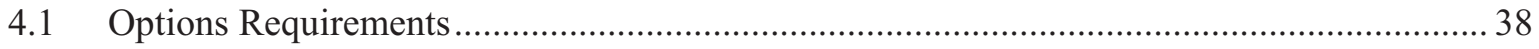

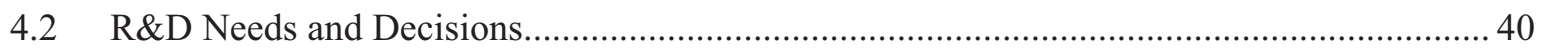

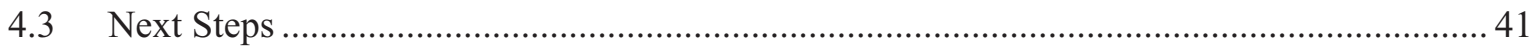

\section{FIGURES}

Figure 1. Approach, Activities, and Goals of Phase I of the Options Study .............................................2

Figure 2. Approach, Activities, and Goals of Phase II of the Options Study ............................................ 3 
Figure 3. Factors Affecting Deep Geologic Disposal for an Integrated Nuclear Fuel Cycle Related to Engineered Repository Performance in a Geologic Environment for Various Geologic Environments and for Undisturbed and Disturbed Conditions 6

Figure 4. Decay Heat from LWR UNF with 51 GWd/MTIHM Discharge Burnup............................... 7

Figure 5. An Example of Total Dose and Main Contributing Radionclides for Disposal of UNF in a Thick Saturated Clay Layer [9] 8

Figure 6. An Example of Total Dose and Main Contributing Radionuclides for Disposal of UNF in a Granite Repository [9]. 8

Figure 7. Ingestion Radiotoxicity for Uranium-based and Thorium-Based Fuel used in an LWR for both Once-through (UNF) and Recycle (HLW) Options. 10

Figure 8. Examples of the reported cost ranges for light water reactors including recommended values from AFCI cost basis report and reported values for three near-term LWR reactor deployments [38]

Figure 9. Cost distributions for a once-through LWR fuel cycle, a recycle fuel cycle with a fast reactor ("1 Tier"), and a recycle fuel cycle with combined once-through LWR and recycle fast reactor (“2 Tier”) [39]

\section{TABLES}

Table 1. Best Attainable Performance for One or More Options in the Range of Uraniumbased Fuel Cycles, Compared to an LWR Once-through Fuel Cycle, Based on Currently Available Information

Table 2. Best Attainable Performance for One or More Options in the Range of Thorium / Fissile-based Fuel Cycles, Compared to the LWR Once-through Fuel Cycle, Based on Currently Available Information

Table 3. Summary Observations on Fuel Cycle Option Capabilities 


\section{ACRONYMS}

$\begin{array}{ll}\text { ADS } & \text { Accelerator-Driven System } \\ \text { AFCI } & \text { Advanced Fuel Cycle Initiative } \\ \text { FCR\&D } & \text { Fuel Cycle Research \& Development } \\ \text { FFH } & \text { Fusion-Fission Hybrid } \\ \text { GFR } & \text { Gas-Cooled Fast Reactor } \\ \text { GTCC } & \text { Greater Than Class C } \\ \text { GWd } & \text { GigaWatt-day } \\ \text { HEU } & \text { High Enriched Uranium } \\ \text { HLW } & \text { High-Level Waste } \\ \text { HTGR } & \text { High Temperature Gas-Cooled Reactor } \\ \text { HWR } & \text { Heavy Water Reactor } \\ \text { IAEA } & \text { International Atomic Energy Agency } \\ \text { IFNEC } & \text { International Framework for Nuclear Energy Cooperation } \\ \text { INPRO } & \text { International Project on Innovative Nuclear Reactor and Fuel Cycles } \\ \text { INS } & \text { Innovative Nuclear Systems } \\ \text { LEU } & \text { Low Enriched Uranium } \\ \text { LFR } & \text { Lead-cooled Fast Reactor } \\ \text { LLW } & \text { Low-Level Waste } \\ \text { LWR } & \text { Light-Water Reactor } \\ \text { MOX } & \text { Mixed Oxide } \\ \text { MSR } & \text { Molten Salt Reactor } \\ \text { MTIHM } & \text { Metric Ton of Initial Heavy Metal } \\ \text { NRC } & \text { Nuclear Regulatory Commission } \\ \text { PWR } & \text { Pressurized Water Reactor } \\ \text { RDD } & \text { Radiation Dispersal Device } \\ \text { SFR } & \text { Sodium-Cooled Fast Reactor } \\ \text { SNM } & \text { Special Nuclear Materials } \\ \text { UNF } & \text { Used Nuclear Fuel } \\ \text { WIPP } & \text { Waste Isolation Pilot Plant } \\ \end{array}$





\section{FCR\&D TECHNICAL INTEGRATION OFFICE OPTIONS STUDY - PHASE II}

\section{INTRODUCTION}

This Options Study, initiated as part of the Advanced Fuel Cycle Initiative (AFCI), and continuing in support of Fuel Cycle Research and Development (FCR\&D), has been conducted with the purpose of evaluating the potential of alternative integrated nuclear fuel cycles to address the issues associated with a continuing or expanding use of nuclear power in the United States, providing information that could be used in identifying potential directions for research and development of nuclear fuel cycle options.[1] An integrated nuclear fuel cycle is defined in this study as the entire fuel cycle, from obtaining natural resources for fuel to the ultimate disposal of used nuclear fuel (UNF) or radioactive wastes. Available information has been collected and reviewed in order to evaluate the ability of an option to clearly address the challenges associated with the current implementation and potential expansion of commercial nuclear power in the United States. Issues such as nuclear waste management, especially the increasing inventory of used nuclear fuel and the current uncertainty about used fuel disposal, and the risk of nuclear weapons proliferation, have contributed to the reluctance to expand the use of nuclear power, even though it is recognized that nuclear power is a safe and reliable method of producing electricity. In this Options Study, current, evolutionary, and revolutionary nuclear energy options are all considered.

The focus in the Options Study is to identify any nuclear fuel cycle technology or option that may result in a significant impact on the issues as compared to the current U.S. approach of LWRs or similar reactors with direct disposal of the UNF, since incremental differences may be difficult to clearly identify and justify due to the large uncertainties that can be associated with the specific causes of the issues. Phase II of the Options Study continues the review of nuclear fuel cycle options that was initiated and documented during Phase I, concentrating on summarizing the potential of integrated nuclear fuel cycles. However, based on the reviews of previous studies and available data, it was not always possible to clearly identify sufficiently large differences between the various fuel cycle and technology options for some of the issues or evaluation measures. For example, there are cases where only incremental improvements with respect to the issues might be achieved, insufficient to clearly rise above the uncertainties, regardless of the fuel cycle being considered,. This Options Study continues to be a comprehensive review of all options, unrestricted by any limitations that may be imposed by economics, technical maturity, past policy, or speculated future conditions. The Phase II report is intended to be used in conjunction with the Phase I report, and much information in that report is not repeated here, although some information has been updated to reflect recent developments.

\subsection{Review of Phase I}

The approach, activities, and goals of Phase I of the Options Study are shown on Figure 1, where it is seen that the issues with the current implementation of nuclear power in the U.S., their root causes, and the evaluation measures for judging the effectiveness of an advanced nuclear fuel cycle were the basis for the study. The study then proceeded to a review of the range of possible nuclear fuel cycle strategies and an assessment of the ability of each strategy to address issues, as documented in Reference 1. A nuclear energy fuel cycle could take one of two fundamental approaches, either a strategy based on the oncethrough use of nuclear fuel followed by direct disposal of used fuel, or a strategy that would process used fuel and employ recycle of one or more elements recovered from the used fuel, with the resulting disposal of used fuel and processing wastes, or in the case where all used fuel is processed, only processing wastes would be disposed. The Phase I review of previous studies indicated that the basic characteristic of the nuclear fuel cycle, once-through versus recycle, may largely determine the ability of a nuclear fuel cycle to address at least some of the issues with nuclear power. It was noted that either a once-through or 
recycle approach could be implemented using the same nuclear technologies, whether using uraniumbased or thorium-based fuels, often with similar results but in other cases with significant differences between technologies that would favor one over another. In Phase I, due to the large number of variations that are possible, it was important to first consider what is possible to achieve before focusing on the details of how to achieve it, using the appropriate fuel cycle and technology choices.

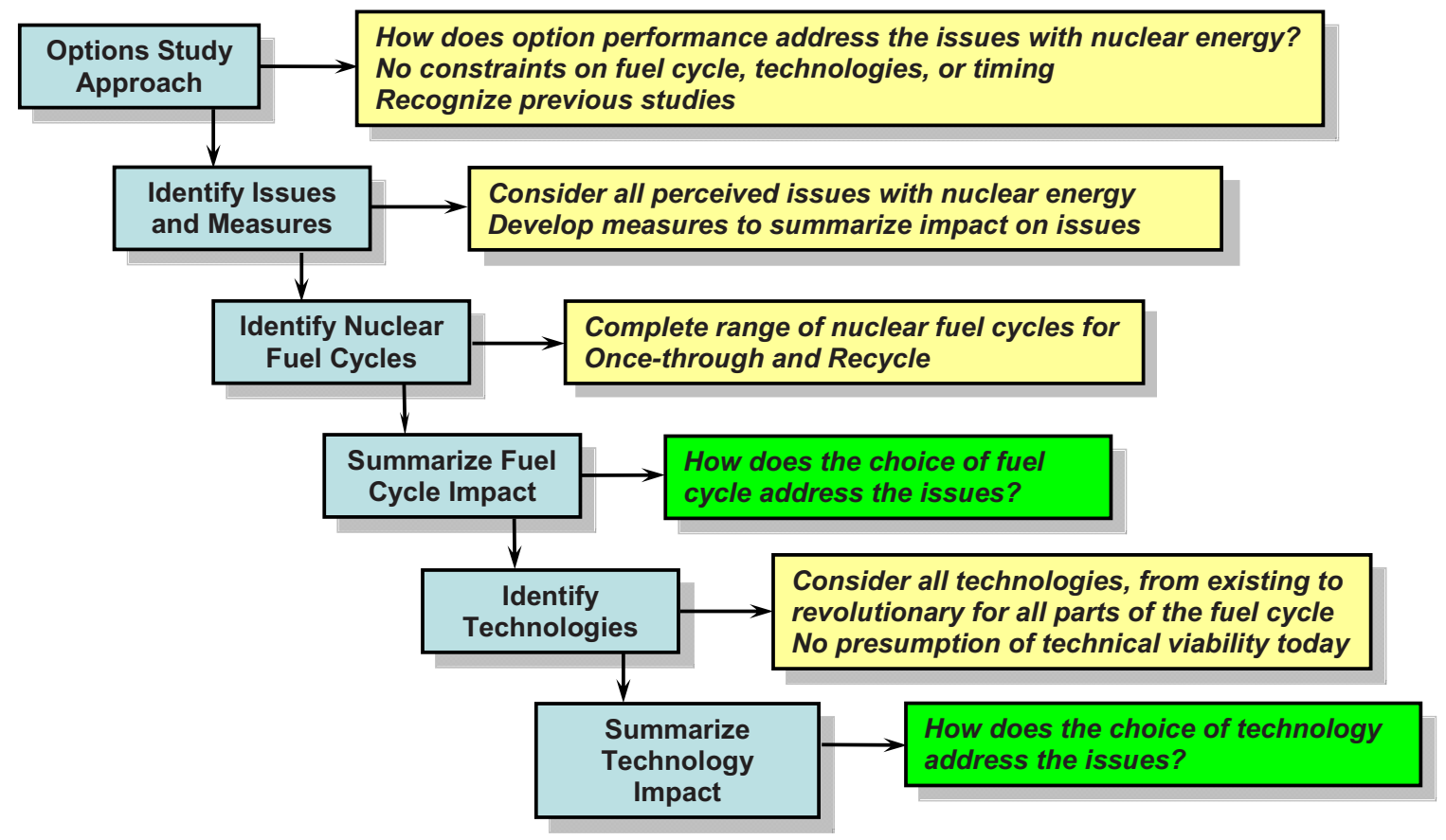

Figure 1. Approach, Activities, and Goals of Phase I of the Options Study

The Phase I report contains a discussion of both once-through and recycle nuclear fuel cycle options, and the basic technology options for all components of a nuclear fuel cycle, summarizing the potential impact on the issues along with the supporting references, which are not repeated in this report. The report concluded with outlining the decisions that would need to be made, and the framework for making the decisions, based on the addressing the issues with nuclear power.

\subsection{Scope of Phase II}

The approach, activities, and goals of Phase II of the Options Study are shown on Figure 2, where it is seen that the first activity was to identify all of the major gaps in information on nuclear fuel cycle and technology options required to meet the goals of Phase II. In coordination with the Systems Analysis Working Group of the FCR\&D program, 6 studies were conducted to support the ongoing Options Study. The studies included investigation of nuclear fuel cycles, including advanced once-through fuel cycles and the use of thorium. Of particular importance was the study on the environmental impact of "front end" activities, i.e., obtaining resources for nuclear fuel, including $\mathrm{CO}_{2}$ emission and energy usage. In comparing nuclear fuel cycle options, not all fuel cycles have the same overall environmental impact, depending on the need for fuel resources as well as disposal requirements.

The evaluation measures were reviewed and slightly modified as a result of the Phase I effort. The next step was to develop the entire range of integrated nuclear fuel cycles for both once-through and recycle, as reviewed in Chapter 3. To facilitate the evaluation process and avoid unnecessary complication, the fuel cycle descriptions were detailed only to the extent necessary to characterize the performance of the fuel cycle, regardless of the specific technology that was used, except in cases where the choice of 
technology was the feature that enabled a significant difference to be obtained. For example, it may not matter which type of thermal reactor is used, as long as the neutron irradiation is effectively represented by a thermal neutron spectrum, or in the case of separations, it may not matter which separations technology is being used, as long as the separations of interest can be successfully performed.

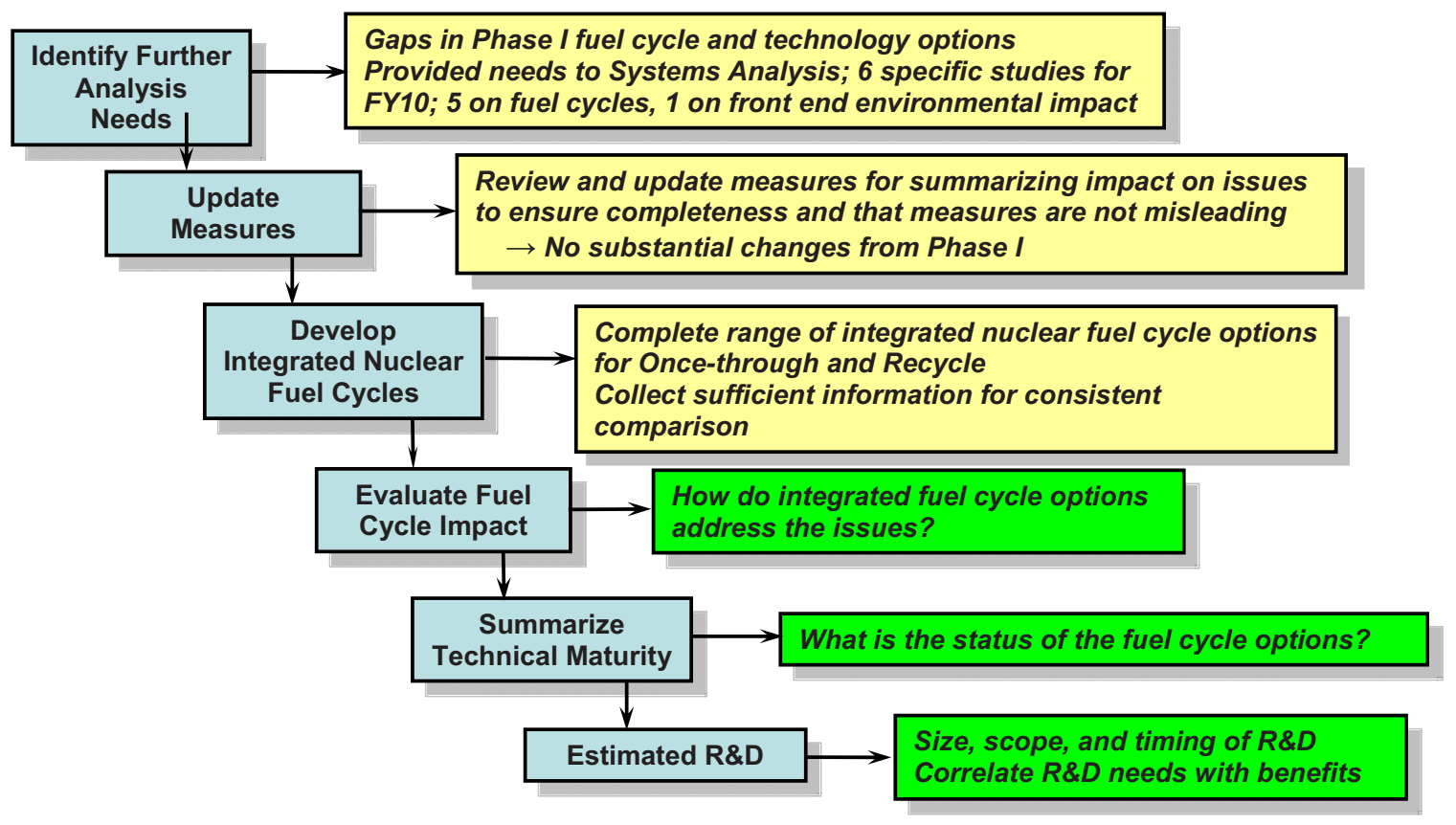

Figure 2. Approach, Activities, and Goals of Phase II of the Options Study

The concept of a significant difference needs to be viewed in the context of the individual measures being used in the study as described in the Phase I report.[1] For many of the measures, an order of magnitude change is considered to be significant, while for other measures, especially those dealing with economics, even relatively small changes may be considered significant due to the large financial commitments associated with nuclear fuel cycle facilities. The fuel cycle options that are capable of making a significant difference are identified in this report, along with discussions on the status of the fuel cycle and specific technologies, and the anticipated R\&D needs for bringing the option to maturity.

\section{ADDRESSING THE ISSUES WITH NUCLEAR POWER}

As described in detail in the Phase I report, review of published documents concerning nuclear power describe the main issues with current U.S. implementation of nuclear power, as follows:

- $\quad$ Nuclear Waste Management - Highly radioactive materials, such as used nuclear fuel (UNF) and some processing wastes and other materials described as high-level waste (HLW), represent a significant long-term health risk due to the presence of a substantial content of long-lived radioactive isotopes, prompting decisions that the only acceptable disposal path would likely be geologic isolation for hundreds of thousands of years or longer. Currently, uncertainty about the ability to provide sufficient assurance of the desired isolation has delayed or prevented implementation of geologic disposal. Many nuclear power activities also create wastes of generally low radioactivity, low-level waste (LLW). While health risk from most low-level waste (LLW) disposal has been judged to be minimal, resulting in licensed disposal using near-surface burial, there is the potential for some 'greater than Class C' LLW in the U.S. that may require geologic disposal as well. Even though the risk from LLW disposal is very low, it has also proved problematic to implement, as 
evidenced by difficulties in siting near-surface burial facilities for the Low Level Waste Compacts in the U.S. Overall, disposal of UNF and radioactive wastes continues to be a major issue. Very-shortlived radioactive materials, even those that are highly radioactive, are managed by short-term storage to allow them to decay, although they are often mixed with HLW or chemically-toxic materials.

- Proliferation Risk and Security - Concerns about global proliferation risk from past, current, and future use of nuclear power and alternative nuclear fuel cycles arise from the connection between the use of civilian nuclear power and the ability to develop nuclear weapons capability:

- $\quad$ both use the same fissile materials; ${ }^{233} \mathrm{U},{ }^{235} \mathrm{U}$, and ${ }^{239} \mathrm{Pu}$,

- many fuel cycle options require deployment of fuel cycle technologies such as uranium enrichment that could produce weapons-usable highly-enriched uranium from natural uranium,

- nuclear fuel cycles employ reactors or other irradiation systems that have the potential to produce weapons-usable materials by neutron irradiation of uranium or thorium,

- nuclear fuel cycles with recycle involve processing of UNF that in principle may provide the ability to separate and recover these fissile materials from UNF.

Proliferation risk is currently considered to be a "host state" issue, where the adversary is considered to be an independent nation, and considers civilian facility misuse, material diversion from civilian nuclear facilities, or the development of clandestine facilities, with the goal of developing and obtaining practical nuclear weapons. As such, proliferation risk is only relevant for countries that do not possess nuclear weapons. It is important to note that proliferation risk is distinct from the security risk of theft by a sub-national or terrorist group, where the assumptions about capabilities and goals are likely to be quite different, and specific attributes of the fuel cycle may have different levels of importance, including the risk that a terrorist attack or sabotage could result in radioactive release from any nuclear power related facility or activity. Security risks are relevant for all countries using nuclear technologies, both nuclear weapons states and non-nuclear weapons states.

- Safety - All facilities and activities, including reactor operation, UNF processing, and transportation and storage of radioactive materials may have safety-related risks due to the potential for accidents that can disperse radioactive materials. Although all nuclear facilities must be evaluated for safety concerns before obtaining a license, residual concerns about safety still exist due to the potentially large consequences of certain accidents. Achieving the desired level of safety may be easier for some facilities or technologies than others, impacting the economics of the fuel cycle as well.

- $\quad$ Sustainability - The ability to sustain nuclear power depends on resolving the other existing issues and will also depend on the availability of natural resources in the future, both for fuel and waste disposal. The environmental impact of the fuel cycle can be an issue if the impact is judged to be significant, as has been questioned recently with respect to uranium mining and related activities. Natural resources required for disposal are also part of sustainability, and connect with the larger concerns about nuclear waste management.

- Economics - Cost of nuclear power has been an issue for several decades, primarily due to the large capital investment required for building nuclear power reactors, and affected by uncertainties about licensing, the time required for plant construction prior to operation, permission to operate the plant once constructed, and cost recovery once the plants have been approved for operation. Addressing the other issues with nuclear power can also impact the cost, and although many studies present favorable costs for nuclear fuel cycles, the disagreements between studies support the observation that the overall uncertainty tends to be very high. In addition, non-technical issues are cited in such studies as being a significant contributor to the cost, such as the cost of financing nuclear facility construction. 
In this Chapter, each issue is covered in detail, reviewing and summarizing the results of the information collected to date. For each issue, the technical implications for fuel cycle performance are presented, providing the background for the discussions of potential fuel cycle options in Chapter 3.

\subsection{Nuclear Waste Management}

Nuclear waste management includes all of the radioactive wastes associated with the nuclear fuel cycle, including wastes requiring geologic disposal such as UNF and certain processing wastes, and LLW that can be disposed with near-surface burial due to the much lower inherent hazard. Short-term storage prior to disposal can also be used as part of a nuclear fuel cycle option to manage very-short-lived radioactive materials, even those that are highly radioactive, allowing them to decay almost entirely and simplifying disposal. It should be recognized that alternative nuclear fuel cycles may also produce other hazardous and non-hazardous industrial wastes, depending on the processes used in the fuel cycle. From analyses supporting the draft Programmatic Environmental Impact Statement for the Global Nuclear Energy Partnership [2] and current industrial waste production, it is expected that such industrial wastes from nuclear fuel cycle activities would be handled as they are today for other industries, and would not present a significant additional burden due to the relative size of the nuclear energy infrastructure, even in cases where significant growth is assumed.

\subsubsection{Fuel Cycle Resource Needs for Waste Disposal}

All use of nuclear power will generate radioactive wastes, whether the used fuel itself is considered as waste, or if recycle is used, the waste products from processing used fuel, with waste disposal considered as an integral part of the fuel cycle. Contaminated equipment, wastes from operations and maintenance, and other wastes all contribute to the total waste production. The primary concern for radioactive waste disposal is the ability to provide the required isolation from the biosphere. For used fuel or highly radioactive wastes, since many of the radioactive materials are hazardous for very long times, and only small amounts can pose a health risk, the consensus has been that deep geologic disposal is the preferred approach. For wastes that are only slightly contaminated, the risk has been judged to be significantly less, and near-surface burial has been approved for such disposal. In both cases, other characteristics of the wastes may be important, such as volume or total mass, e.g., the mass of the waste form matrix as well as the mass of the disposed radionuclides. In reviewing studies on waste production, volume and total mass appear to be influenced by technology choices within a fuel cycle and appear to be amenable to waste reduction technologies or choice that can limit total waste mass and volume.

\subsubsection{Repositories in Deep Geologic Environments}

The need for deep geologic disposal of used fuel and wastes that are highly radioactive has prompted investigation of a number of potential geologic environments in which to site a repository in order to evaluate the capability of the combined engineered repository and geologic environment to isolate these materials, such as the U.S. programs like the Nuclear Waste Terminal Storage Program starting in 1976, and activities created by the Nuclear Waste Policy Act of 1982, leading to the Yucca Mountain repository project.[3] The engineered repository includes all design features, such as disposal packages and any other engineered barriers to the release of radioactive materials, since acceptability of deep geologic disposal is determined by estimates of the peak dose rate for releases from the repository,[4] which can be viewed as being determined by two factors, one, the radiotoxicity of the disposed inventory, and two, the degradation and transport characteristics of the engineered repository and the geologic environment. These two factors are analogous to the "dose-response assessment" and the "exposure pathway analysis" that is used for consequence evaluation in risk analysis.[5] In the following sections, using data from these and the other studies listed in the Phase I report, each potential combined engineered repository and 
geologic environment is reviewed with a focus on identifying the used fuel or waste contents or characteristics that affect the performance of a repository.

In considering the sensitivities of an engineered repository and the geologic environment affecting the ability to isolate the disposed materials, the analysis can be divided into two aspects, one for the performance under "nominal" undisturbed conditions of the repository, and the other considering the effects of disturbances, as shown in Figure 3, but both aspects must be fully considered for an overall performance assessment. Nominal undisturbed performance is where the conditions used for evaluating the geologic environment and designing the engineered repository are assumed to persist, while disturbed performance evaluates the effects of any disturbances that alter these conditions, either the engineered repository, the geologic environment, or both. In conducting an assessment of overall performance of a geologic repository, these two aspects can be considered either separately or combined into a single overall assessment, but both aspects need to be considered to arrive at an overall estimate of performance that would be required for licensing. For the purposes of understanding and evaluating the capabilities of an alternative nuclear fuel cycle to affect issues with deep geologic disposal, it is useful to consider undisturbed and disturbed performance separately, as summarized in Figure 3, mainly because it appears that nominal undisturbed performance can be predicted with comparatively lower uncertainty, while the probability of occurrence of disturbed conditions in the future is inherently uncertain, especially for human activities, and evaluating the consequences of the disturbance require numerous assumptions about the nature and effects of the disturbance.

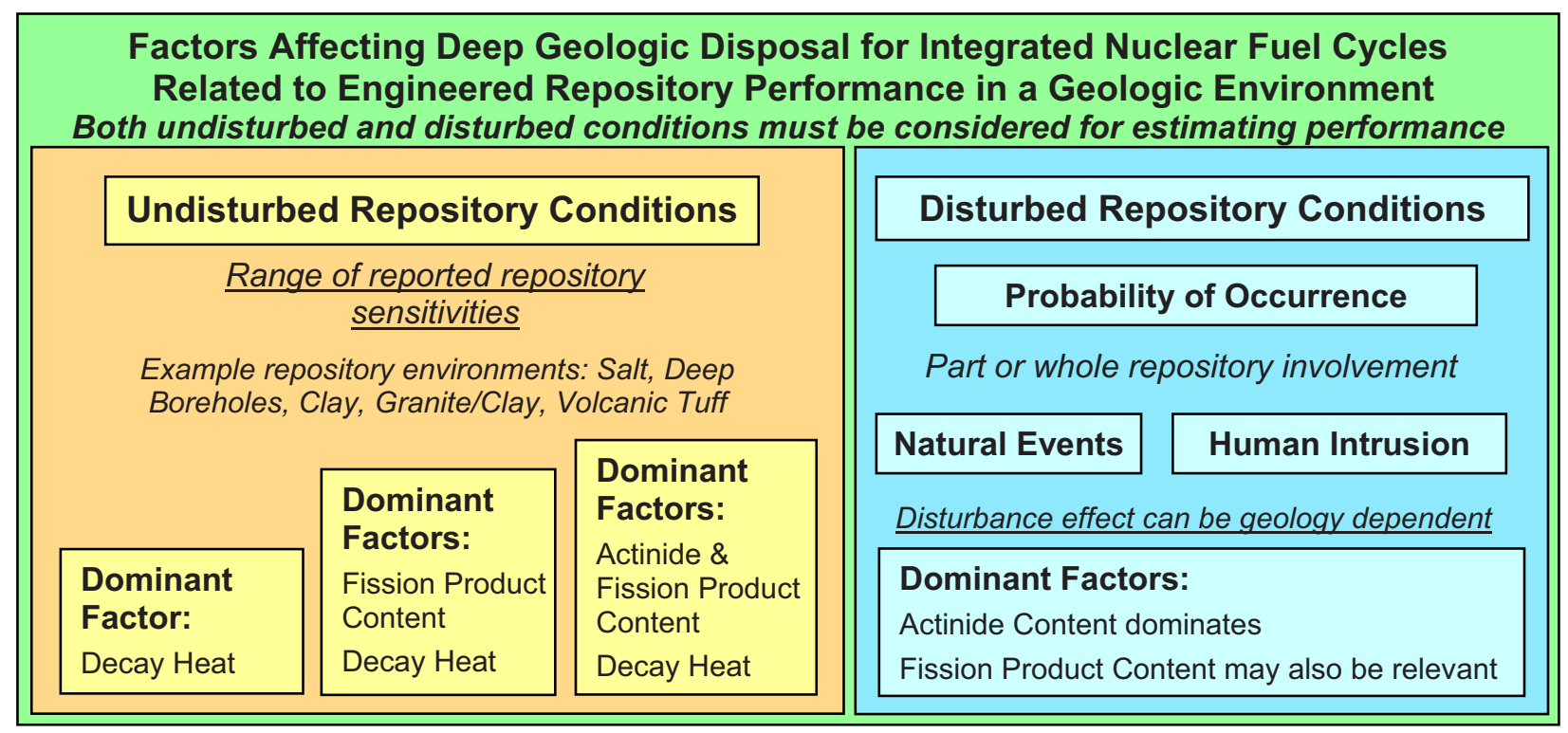

Figure 3. Factors Affecting Deep Geologic Disposal for an Integrated Nuclear Fuel Cycle Related to Engineered Repository Performance in a Geologic Environment for Various Geologic Environments and for Undisturbed and Disturbed Conditions

\subsubsection{Repository Performance for Nominal Undisturbed Conditions}

The performance of an engineered repository in a deep geologic environment under nominal undisturbed conditions assumes that the conditions used for evaluating and designing the repository remain unchanged during the time the repository is required to isolate the emplaced radioactive materials, i.e., the functional lifetime of the repository. In reviewing the studies on engineered waste repositories in various geologic environments, there appear to be three useful groupings with different sensitivities to waste stream characteristics, as shown on the left side of Figure 3. 


\section{Decay Heat as the Dominant Factor}

There are some repository options where decay heat is the dominant sensitivity affecting repository performance and nominal undisturbed isolation performance does not strongly depend on the radionuclides in the waste. Examples may include [6-8]:

- Disposal in certain salt deposits, where temperature in the repository needs to be limited to prevent water migration and salt deformation

- Disposal in deep boreholes, where the temperature needs to be limited to prevent establishing a driving force for vertical convection

For these deep geologic disposal options, the implication for an integrated fuel cycle appears to require limiting the volumetric decay heat generation rate, likely to levels much lower than is typical for UNF.

Decay heat generation in UNF decreases rapidly after discharge from the reactor, as does the decay heat for any wastes generated by processing the UNF. As shown in Figure 4 for UNF from an LWR with 51 $\mathrm{GWd} / \mathrm{MTIHM}$ discharge burnup, the decay heat is dominated by fission products up to about 60 years after discharge. Decay heat from actinide elements such as plutonium and americium dominate after that time. The acceptable level of decay heat would be determined by detailed thermal analysis of the proposed engineered repository and the geologic environment, including the decay heat at time of disposal and the integrated decay heat from the time of repository closure until the peak temperatures in the repository is attained. This may require consideration of the importance of the decay heat from both actinide and fission product elements, although for some repository environments, only the shorter-term decay heat from fission products may be important. Another aspect is the time between discharge from the reactor and placement in the disposal environment. If shorter-term decay heat is important, interim storage of UNF or HLW for several decades or longer may be an effective means of reducing this shortterm decay heat to levels acceptable for repository disposal.

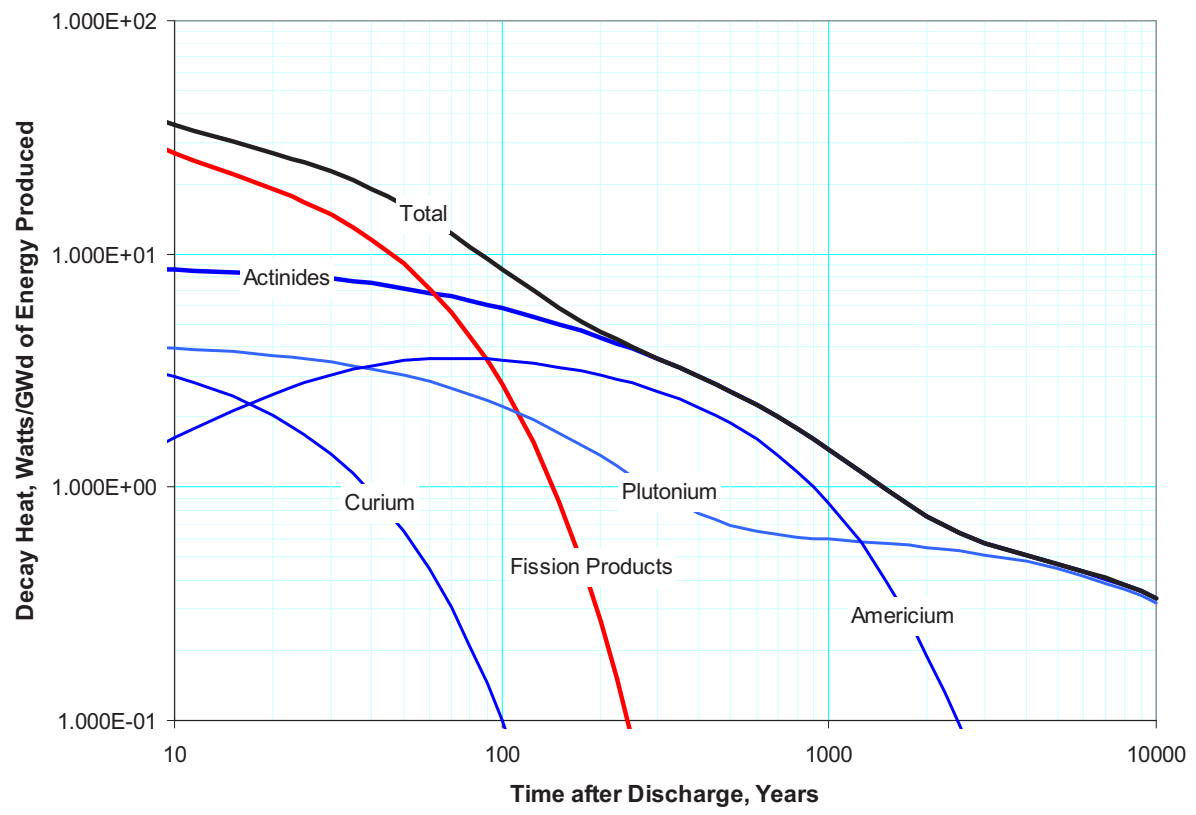

Figure 4. Decay Heat from LWR UNF with 51 GWd/MTIHM Discharge Burnup. 


\section{Fission Product Content and Decay Heat as Dominant Factors}

There are some repository options where the nominal undisturbed repository isolation performance appears to be sensitive to both decay heat and the quantity and specific inventory of fission products, as some fission products have significant potential release pathways. Examples may include:

- Disposal in thick clay layers with saturated reducing conditions

- Disposal in a hard rock environment using clay with saturated reducing conditions surrounding disposal packages, as for a repository in granite.

The fission product content affects the peak dose rate for individual exposures. Examples are shown in Figures 5 and 6 for disposal in a thick clay layer and for a repository in granite. The dominant fission product isotopes can be identified in these figures. Most of the fission products are not amenable to recycle for transmutation, but some can be recycled such as ${ }^{129} \mathrm{I}$ and ${ }^{99} \mathrm{Tc}$. As with the previous case, decay heat is an important parameter, affecting both repository performance and use of repository space. However, both actinide elements and fission products can be important for decay heat.

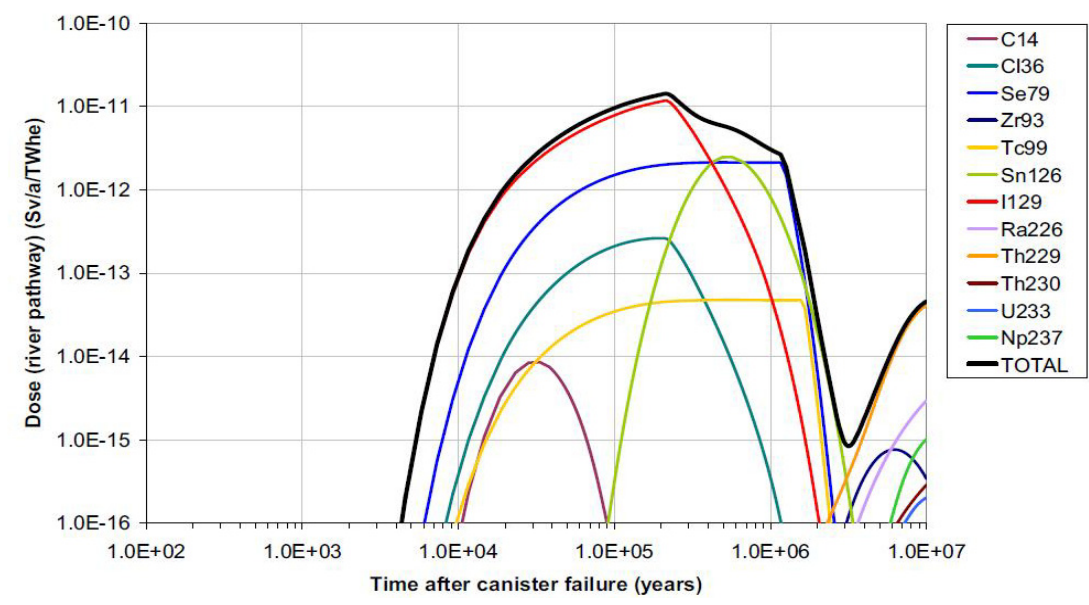

Figure 5. An Example of Total Dose and Main Contributing Radionclides for Disposal of UNF in a Thick Saturated Clay Layer [9]

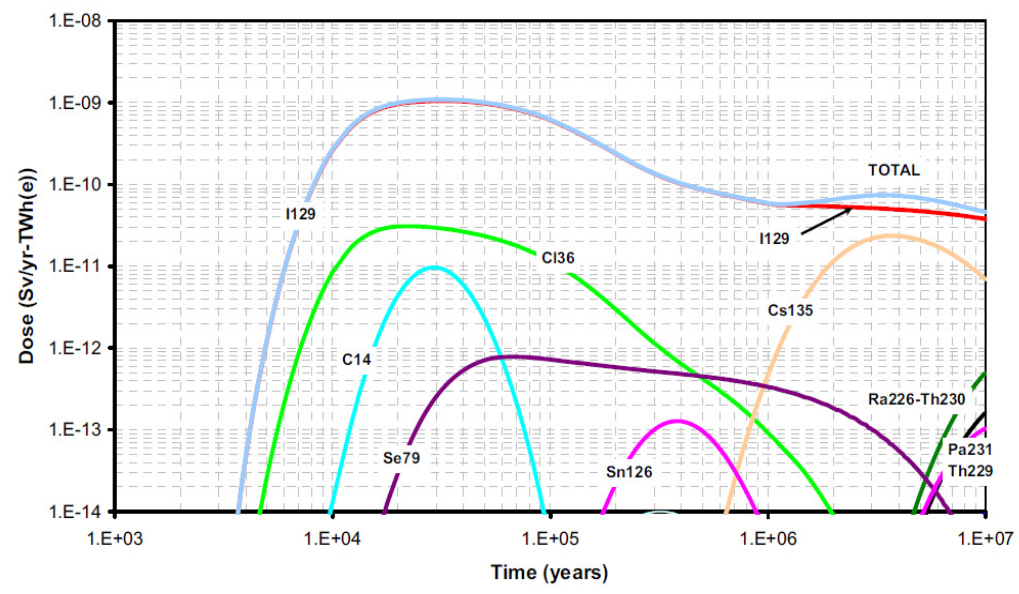

Figure 6. An Example of Total Dose and Main Contributing Radionuclides for Disposal of UNF in a Granite Repository [9] 


\section{Actinide Content, Fission Product Content and Decay Heat}

There are some repository options where both actinide and fission product content can be important to the nominal undisturbed repository isolation performance, as well as decay heat, as release pathways for radionuclides might develop. Examples may include:

- Disposal in volcanic tuff in an unsaturated oxidizing environment

Assessments of the resulting dose rate for releases from such a repository show that both actinides and fission products can be important to the peak dose rate, as listed in Figure 3.[10] Decay heat is an important parameter for affecting repository performance and use of repository space in this case as well. Both actinides and fission products contribute to the decay heat. Depending on the repository design, only the fission products may be relevant to the decay heat, primarily at shorter times, while for others, the integrated decay heat dominated by the actinides can be important, primarily at longer times.[11]

The differentiation of waste disposal impacts between actinides and fission products can be important for the fuel cycle option because these two categories of materials (fission products and actinides) have very different characteristics in neutron irradiation, where some actinide isotopes can be actively involved in the fission and energy production while fission products absorb neutrons.

\subsubsection{Disturbed Performance}

In reviewing the studies on repository performance, it is seen that disturbances to a geologic repository can be important in evaluating overall performance, since all repositories can have releases as a result. Disturbances can be caused by human activities or by natural events. Human intrusion includes exploratory drilling and mining, and examples of natural events are igneous and seismic episodes. In both cases, the repository environment is disturbed from the nominal undisturbed conditions that were assumed in the development of the repository, with implications for the subsequent ability of the repository to provide the desired isolation of the disposed materials. The studies for different repository environments demonstrate the importance of considering disturbances to the repository, including situations where repository performance is dominated by the effects of disturbances.

The effects of human intrusion appear to vary with repository environment. For example, a repository in salt could be vulnerable to exploratory drilling, resulting in penetration of the salt and surrounding layers, with the potential for allowing water into the repository. In such a case, all of the disposed materials may eventually be at risk of release if water enters the repository, due to the resulting corrosion of disposal packages and contents, although there is also the risk of direct exposure from the contents of the disposal package that was breached. On the other hand, drilling through a repository in volcanic tuff or clay might only affect the waste package encountered with no further consequences since water is already present in those environments. It is not possible to provide a scientific estimate of the probability of human intrusion, although it is recognized that the likelihood of intrusion may be reduced by appropriate selection of the repository site away from known natural resources. Since the contents of one or more waste packages would be at risk, both the actinide and fission product elements contributing to the radiotoxicity could be important to the peak dose rate associated with these events, as shown in Figure 7. The radiotoxicity is plotted for both uranium-based and thorium-based $\left(\mathrm{Th} /{ }^{233} \mathrm{U}\right)$ fuel used in an LWR on a per GWd basis for both once-through and recycle approaches. As can be seen from Figure 7, the radiotoxicity for UNF from LWRs is similar whether uranium-based or $\mathrm{Th} /{ }^{233} \mathrm{U}$ fuel is used. Also, the fission product contribution is shown, which would be the lower limit for reducing radiotoxicity when actinide recycle is used, i.e., there are no losses of actinides to the wastes.

Natural events causing disturbances are large-scale phenomena that conceivably affect all of the disposal packages in the repository. Once the packages are breached, the entire inventory is available for release and transport. Depending on the assumptions made about the exposure pathway, again both actinide and 
fission product elements contributing to the radiotoxicity can be important to the peak dose rate for such events. Predicting the probability of future natural events is also uncertain, although with the current level of understanding for crustal phenomena, past history can likely be used as a reliable approximate indicator of probability of occurrence.

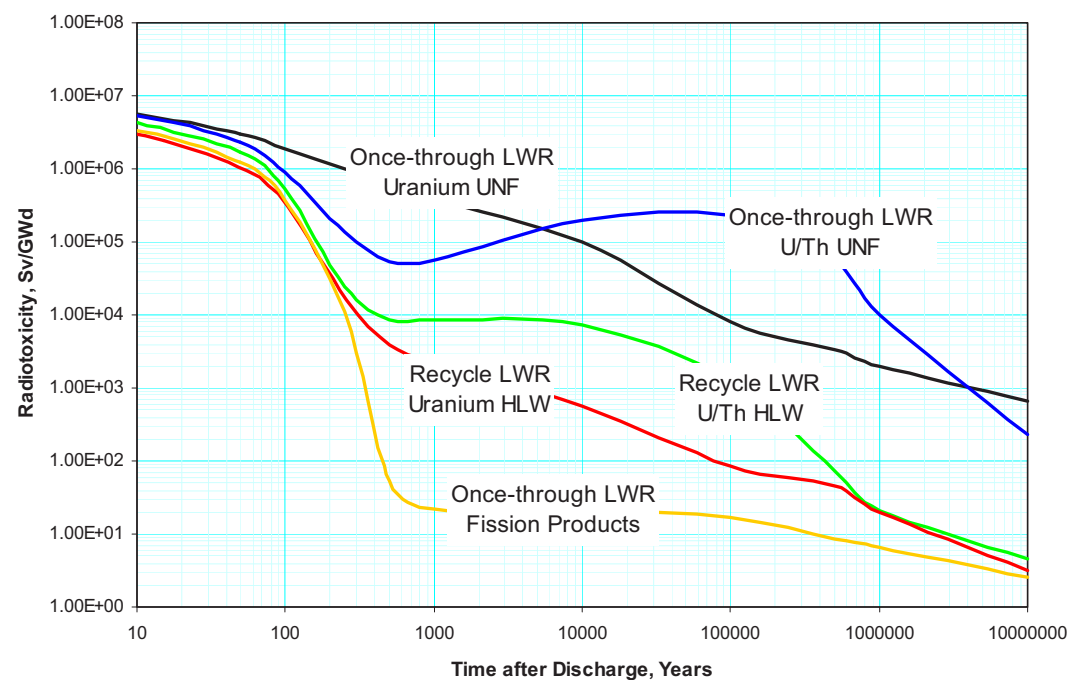

Figure 7. Ingestion Radiotoxicity for Uranium-based and Thorium-Based Fuel used in an LWR for both Once-through (UNF) and Recycle (HLW) Options

An important implication for fuel cycle options from the preceding discussion is that there is no single, simple or universal correlation between fuel cycle waste characteristics and disposal challenges. The importance of waste stream characteristics depends on the details of the disposal host environment and the repository design, and even then can be altered by potential disruptive processes.

\subsubsection{Near-Surface Disposal Environment Characteristics - LLW}

The term "low-level waste" encompasses a wide range of materials. Management of these wastes is regulated by the NRC under 10CFR Part 61. In the U.S., LLW waste is classified into A, B, C and 'greater than class C' GTCC, based on activity and half-life. Class A waste is the lowest level of activity and shortest half-life, and comprises the largest volume of LLW. Class B and C wastes have more concentrated radioactivity, and may have some longer half-life activity. Most of the volume of LLW produced in the nuclear energy industry is in Class A, but most of the activity is in Class B and C. These wastes include items that have become contaminated with radioactive material or been activated by neutron exposure. Operational wastes such as shoe covers, clothing, wiping rags, mops, filters, tools, etc. contribute to volume. Typically, the total radioactivity is low and the radionuclides are primarily of short half-life. LLW is typically disposed of in near-surface burial facilities. Drums or other handling containers are buried in prepared trenches or bunkers. The facility typically includes engineered control of water infiltration and drainage. This provides adequate isolation for the short time required for most of the radioactivity to decay.

There are currently three operating LLW disposal sites in the U.S., there have been others in the past. In the event there is need for increased LLW disposal capacity in the future, it is generally accepted that the requirements for selecting suitable LLW sites should not be as demanding as for HLW/UNF disposal. However, this does not imply that such siting will be easy. In 1985 Congress enacted the "Low Level Waste Amendments Act" to make states responsible for future LLW disposal and defined a process to prompt development of multiple disposal sites by regional 'compacts'. This compact process has yet to 
produce any new LLW disposal facilities. Many regional compacts have formed, and several have broken up and reformed - usually over the process of selecting a 'host state'. A number of states have chosen to 'go alone' as an unaffiliated state - in some cases after having been selected as a compact 'host state' and then leaving that compact. At this time there are 10 compacts and 10 unaffiliated states. Some compacts are making slow progress toward siting a LLW facility, and some are not. Whether this process will ultimately be a success or a failure is not yet clear.

GTCC waste is contaminated beyond specific limits that define Classes A-C, and is typically treated differently. There is need for greater isolation from the accessible environment, and a longer time-period for isolation than for LLW, but not as severe as for HLW. In some countries, there is a category of 'intermediate level waste' between LLW and HLW that roughly correlates with US GTCC. There is no current disposal pathway for GTCC waste in the US. However, DOE-EM has an ongoing program to develop such disposal capacity. Disposal pathways under consideration include using a deep geologic repository such as for HLW, hardened near-surface disposal vaults and intermediate depth boreholes. Environment requirements for GTCC disposal sites are likely to be more stringent than for other LLW sites, but may be less stringent than for HLW/UNF disposal. Cost, capacity constraints, and specific waste characteristics of most concern cannot be determined until a representative disposal facility is developed. At this time, there has been no effort to site a GTCC facility in the US. Such a siting process is likely to be more difficult than creating new LLW facilities, but may be less difficult than development of a HLW/UNF disposal facility. This is one reason that just adding GTCC to any deep geologic repository for HLW/UNF is considered by some to be the easiest path forward. It can be noted that one intermediate depth borehole "greater confinement disposal facility" for defense related wastes was developed at the Nevada Test Site, and could serve as a precedent for GTCC. This facility is now closed and was not licensed for civil use.

While HLW and UNF tend to dominate waste management considerations in evaluating fuel cycle options, the LLW generation and characteristics must also be considered. Specific technologies can produce larger or smaller quantities of LLW, and of very different characteristics. For example, fuel reprocessing often produces quantities of LLW, and with activities greater than typical reactor operations. Fabrication of transuranics fuel could also result in quantities of higher activity LLW. Where this difference could become most important is in the generation of GTCC waste. While current quantities of civilian GTCC are small, advanced fuel cycle technology could produce larger quantities, perhaps beyond the capacity of current GTCC management planning.

\subsubsection{Technical Implications for a Nuclear Fuel Cycle Option}

Nuclear waste management is one of the major issues facing the use of nuclear power. Based on the published information reviewed for this study, the technical implications for the remainder of an integrated fuel cycle as a result of specific geologic environments depend on the relative importance of nominal undisturbed performance and the effect of disturbances. In all cases, it also appears that uncertainties about the repository environment and exposure pathways may remain large, in part due to the fundamental complexity of a geologic environment and spatial variations in characteristics, although some environments may have lower uncertainties than others. As a result, there is no single simple answer for what a nuclear fuel cycle option needs to do to benefit deep geologic disposal, aside from the fundamental principle that the less hazardous material placed in the environment, the better.

\section{Geologic Disposal - Performance Dominated by Nominal Undisturbed Conditions}

Using Figure 3, there are three groupings of implications for fuel cycle options for undisturbed geologic disposal, as follows:

- Disposal environments where decay heat is the dominant parameter affecting repository performance 
- The decay heat of the fission products can be mitigated or eliminated with interim storage due to the relatively short term that they dominate decay heat, up to about 60 years, while their effect is essentially gone by about 300 years. Alternatively, an integrated fuel cycle could use separations to advantage to isolate high decay heat fission products from the remaining wastes, storing only those fission products for an extended period of time. However, some of the major decay heat contributors such as ${ }^{90} \mathrm{Sr}$ and ${ }^{137} \mathrm{Cs}$ are not considered to be effectively transmutable by neutron irradiation, so recycle of these elements would not be effective.

- The decay heat from the actinides persists for longer times, at least a thousand years, and interim storage would likely not be effective. If actinide decay heat causes difficulty with satisfying repository temperature limits, separation and recycle of the actinides or long-term storage (many hundreds of years or longer) are the only options to help improve use of repository space.

- Disposal environments where the dominant parameters affecting repository performance are fission product content and decay heat

- Alternative nuclear fuel cycles are not likely to be effective for the fission product content since some of the dominant fission product isotopes are not amenable to transmutation by neutron irradiation.

- Decay heat is an operational and engineering issue in this case, although the lower temperature limits for disposal in saturated clay increase the importance of the shorter-lived fission products, implying that interim storage could be an effective approach to increase utilization of disposal space. Whether the decay heat from the longer-lived actinide elements is important depends on the details of the disposal site, and if proved to be important, separation and recycle would be effective in increasing repository space utilization.

- Disposal environments where the dominant parameters are actinide content, fission product content, and decay heat.

- Recycle of the actinide elements, including uranium, can be done effectively with many nuclear fuel cycle options.

- Decay heat is an operational and engineering issue for such repositories, and separation and recycle of actinides, along with separation and separate storage of shorter-term fission products cesium and strontium, can be effective in optimizing utilization of repository space.

As discussed earlier, the distinction between fission product and actinide impacts is important to fuel cycle options because of the differing characteristics of these materials in fuel cycle technologies.

\section{Geologic Disposal - Performance Dominated by Nominal Disturbed Conditions}

If the effects of disturbances dominate the expected performance of the repository, uncertainty will be very high, in proportion to the ability to predict such future events. For the two types of disturbances, human and natural, the importance of the characteristics of the disposed materials may vary considerably, as follows:

\section{Human Intrusion}

- For human intrusion into a repository where no groundwater is present for undisturbed conditions, such as by drilling into the repository, the effects can be significant, in proportion to the amount of disposed materials affected by the intrusion and the assumptions made about subsequent exposure pathways. In the case of salt, which was initially the preferred option in the U.S., the potential for water entry into the entire repository as a consequence is extremely important, as evidenced by the earlier abandonment of a salt disposal site in Kansas in the U.S. mainly due to the uncertainty about locating all of the existing drilled penetrations from earlier exploration for natural resources such as water, gas, and oil.[12-14] Under such conditions, it would seem that the only approach to reducing 
the resulting peak dose rate from such a failure of the repository boundary is to lower the radiotoxicity of the disposed inventory, unless other mitigating factors are present to retard radionuclide transport. This can be accomplished either by restricting the inventory or by separating and recycling the dominant peak dose rate contributors. Both actinides and fission products may be important, according to the radiotoxicity shown in Figure 7, and depending on the assumptions and characteristics of the resulting exposure pathways.

- For human intrusion into a repository where groundwater is always present, the effects of human intrusion, as reported in studies to date, appear to be relatively minor. Due to the presence of water under normal conditions, drilling through such a repository is only expected to affect the disposal package that is encountered, and the consequences are necessarily small due to the limited inventory that is affected. As a result, lowering the inventory in the disposal package of those isotopes dominating the exposure could be effective, but that would depend on the planned inventory and the associated hazard for each waste package. An alternative fuel cycle may have little or no effect in this case, depending on the projected disposal package contents.

\section{Natural Events}

- For a repository with no releases for undisturbed conditions, the effects of natural disturbances can be pronounced, as evidenced by the controversy for the WIPP repository concerning debate about the potential for future dissolution of the salt layer by groundwater.[14] Other natural events, such as seismic or igneous events, are also considered. In all of these cases, the scale of the disturbance is such that studies assume that the entire inventory of the repository may be at risk and released to the repository environment. Depending on the assumed exposure pathway, both actinide and fission product elements can be important for such conditions, and reducing the dose rate resulting from such disturbances would require lowering the radionuclide inventory in the repository, either by reducing the amount disposed or by separating and recycling the dominant elements to lower their inventory in the repository.

- For a repository with limited releases, the effects of natural disturbances are similarly large, although only seismic and igneous events are likely to be relevant since water is already present. As with the previous case, the large scale of such disturbances results in the assumption that the entire inventory of the repository is at risk and released to the repository environment, and any consequences depend on further assumptions for the exposure pathway. In the case of Yucca Mountain, the dose rate for the igneous intrusion event is dominated by isotopes of the actinide elements.[15] Reduction of the repository inventory would be required to lower peak dose rate, either by reducing the amount disposed or by separating and recycling the dominant elements to lower their inventory.

Overall, the consequences of disturbances can be reduced by lowering the inventory in the repository, which may have the effect of lowering the importance of the disturbance events to the overall performance of the repository, increasing confidence that the repository would provide the desired isolation.

\section{Geologic Disposal - Performance Determined by Both Nominal Undisturbed and Disturbed Conditions}

The studies that have been reviewed demonstrate that both nominal undisturbed conditions and disturbed conditions would likely be considered in developing the performance assessment of geologic disposal. For any alternative fuel cycle, the geologic disposal environment and any associated engineered systems should be considered as part of the integrated fuel cycle since it will determine what, if any, impact the alternative fuel cycle would have on waste management. For identifying those fuel cycles that may be able to make a significant difference to the current nuclear waste management situation, measures to address both undisturbed and disturbed conditions are considered. 


\section{Low-Level Waste Disposal}

Low level waste generation is unavoidable. Choice of fuel cycle and the specific technologies can have a direct effect on the amount of low-level waste, and opportunities for waste reduction. Generation of significant quantities of GTCC waste could have a substantial impact on waste management requirements.

\subsection{Proliferation Risk and Security}

As a preface to the review of the proliferation risk and security issues, it is important to clearly distinguish between these two separate, but related, issues. According to the International Atomic Energy Agency (IAEA), the term "proliferation risk" is currently reserved to "host state" issues, where the "adversary" of concern is an independent nation.[16] As a result, proliferation risk considers facility misuse and material diversion from civilian nuclear power facilities by the state itself, with the goal of developing and obtaining nuclear weapons or nuclear explosive devices, e.g. a test device. Timely detection of facility misuse or material diversion is of fundamental importance to deterring such activities, and is the purpose of the IAEA safeguards system and the international legal regime on which IAEA safeguards rest. More broadly, the potential for undeclared nuclear facilities and activities to exist, in some cases in close proximity to safeguarded facilities (e.g., the case of Iraq prior to 1991), demonstrates that proliferation risk is not confined to civil nuclear facilities, and that measures to reduce risks associated with declared facilities do not address the full range of proliferation risk.

The attractiveness of materials that could be recovered from the facilities, or produced by or through the use of material diverted from the facilities, affects the ability of attempts at proliferation to succeed. Limiting the availability of nuclear technologies through export controls, and developing nuclear technologies that would be inherently more resistant to diversion and misuse, have been proposed as approaches to address proliferation risk. Effective safeguards for such facilities are essential, as are effective controls on nuclear exports and transfers of technology that subsequently might be misused, e.g. the current U.S. government policy for limiting the transfer of enrichment and reprocessing technology.

The issue of proliferation risk is distinct from the security issue, which is concerned with the theft of potentially weapons-usable materials from civilian facilities by a sub-national or terrorist group (the adversary) or the effects of sabotage. With the trend, particularly since $9 / 11$, of assuming increasingly sophisticated capabilities of such groups, the goal of such groups is assumed to be development of a "nuclear explosive device", i.e., a nuclear weapon of uncertain performance, or an improvised nuclear explosive device, or other weapons using radioactive materials, such as radiation dispersal devices, (RDDs). Prevention of theft or sabotage, and carried out through attack by an external group, an "insider" , or a combination of the two, attack is the purpose of security and is addressed through physical protection measures an domestic nuclear material control and accounting systems that would identify what was stolen and facilitate its recovery. The attractiveness of materials in the fuel cycle is clearly relevant to the terrorist threat. In the following discussion, past studies concerning both issues are reviewed and the implications for an alternative fuel cycle are summarized, considering that assumptions about adversary capabilities, motivations, and goals may be quite different between the two issues of proliferation risk and sub-national risk and that specific attributes of the fuel cycle can have different levels of importance for each issue.

\subsubsection{Proliferation Risk}

Risk of nuclear weapons proliferation is a global issue concerning independent nations that currently do not possess nuclear weapons. While the use of alternative fuel cycles within the U.S. does not directly pose a proliferation risk since the U.S. is a nuclear weapon state, there is concern about the spread of sensitive technologies (those related to uranium enrichment and reprocessing) that may be implemented in the U.S. Today's proliferation risk can be connected with the past, continuing and expanding global 
use of nuclear power, since nuclear power requires the use of fissile materials such as ${ }^{233} \mathrm{U},{ }^{235} \mathrm{U}$, or ${ }^{239} \mathrm{Pu}$, which are also potentially usable in nuclear weapons and are termed special nuclear materials (SNM). The ${ }^{235} \mathrm{U}$ is typically obtained from enrichment of natural uranium while the ${ }^{233} \mathrm{U}$ and ${ }^{239} \mathrm{Pu}$ are created as a result of neutron irradiation of thorium and uranium, respectively, in a reactor or other neutron irradiation environment. When considering civilian nuclear power activities, the usability of the SNM can depend on other characteristics such as the isotopic distribution for each element, i.e., the material attractiveness, which is affected by the percentage that is fissile and the presence of other isotopes that complicate or may prevent weapons use, among other aspects.

As a result, the issue of proliferation risk has been considered since the beginning of the nuclear age. Numerous studies have been performed by international and national organizations, expert groups, scientific panels, and individual researchers since the 1940's. In reviewing such studies, it is apparent that while the basic issue of preventing the acquisition and use of SNM in nuclear weapons does not appear to have changed, the maturing and global availability of nuclear technologies has prompted an evolution in the manner in which proliferation risk is considered and evaluated. Technology issues are an important part of this picture, but not the most important. An elaborate set of institutional measures, including international safeguards, nonproliferation treaties and agreements, export controls, etc. has developed over time, and looking forward, the potential contribution of fuel assurances and cradle-tograve arrangements covering both the supply and final disposition of nuclear fuel help define the focus of IFNEC. Ultimately, technology and institutional measures must work together. Some of the more prominent examples are used to illustrate the nature of proliferation risk and to explain the summary observations presented in this report. [17-20]

The issue of evaluating proliferation risk has prompted the development of assessment methodologies. $[21,22]$ These methodologies emphasize the point that the evaluation of proliferation risk by considering proliferation resistant features is largely a subjective process, such as the following statement from the IAEA illustrates (emphasis added):[18]

"INPRO has produced one basic principle that requires that proliferation resistance features and measures be implemented throughout the full life cycle for INS (Innovative Nuclear Energy Systems) and that both intrinsic features and extrinsic measures be utilized. To comply with this basic principle requires that the attractiveness of nuclear technology with respect to its suitability for conversion into nuclear explosive devices be low; the diversion of nuclear material be difficult and be detectable; the commitment and obligations of States be adequate; multiple features and measures be incorporated in the INS covering plausible acquisition paths of fissile material for a nuclear weapons programme; and that the combination of intrinsic features and extrinsic measures be optimized during design and engineering to provide cost-effective proliferation resistance. A detailed acquisition pathways analysis is required for each component of the INS as an input for the INPRO assessment. Effective use of intrinsic features can assist with minimizing the impact of safeguards implementation. Country profiles would be prepared to evaluate the commitments, obligations and policies of states, both technology developer states and technology user states, regarding non-proliferation. RD\&D is needed in a number of areas, in particular, in developing a process to assess the proliferation resistance of a defined INS, taking into account the respective maturity level of the INS and the level of detail available."

This is further delineated by the accompanying paragraphs from the same reference (emphasis added) [18]:

"Intrinsic features consist of technical features that: a) reduce the attractiveness for nuclear weapons programmes of nuclear material during production, use, transport, storage and disposal, including material characteristics such as isotopic content, chemical form, bulk and mass, and radiation properties; b) prevent or inhibit the diversion of nuclear material, including the confining of nuclear material to locations with limited points of access, and materials that are 
difficult to move without being detected because of size, weight, or radiation; c) prevent or inhibit the undeclared production of direct-use material, including reactors designed to prevent undeclared target materials from being irradiated in or near the core of a reactor; reactor cores with small reactivity margins that would prevent operation of the reactor with undeclared targets; and fuel cycle facilities and processes that are difficult to modify; and d) that facilitate nuclear material accounting and verification, including continuity of knowledge.

Five categories of extrinsic features are defined, as follows: a) commitments, obligations and policies of states, such as the Treaty on the Non-Proliferation of Nuclear Weapons and the IAEA safeguards agreements and protocols additional to such agreements; b) agreements between exporting and importing states on exclusive use of nuclear energy systems for agreed purposes; c) commercial, legal or institutional arrangements that control access to nuclear material and technology; d) verification measures by the IAEA or by regional, bilateral and national measures; and e) legal and institutional measures to address violations of measures defined above."

Country capabilities and intentions can and do evolve over time, such that an evaluation of proliferation risk completed at one point in time may no longer be valid later, especially under a different set of circumstances with respect to underlying technical capabilities or diplomatic motives and situations. The transfer of certain technologies may also convey "know-how" to a state that could subsequently form the basis for clandestine facilities, even if a declared nuclear energy system is not misused. These considerations appear to greatly complicate proliferation risk assessments and any conclusions that may be reached.

Review of recent proliferation assessments further supports this view, where the results depend to a great extent on assumptions that are made about adversary capabilities and intent.[23,24] Even with fuel cycle technologies for which proliferation resistant features were claimed, assumptions about host state capabilities and actions tended to eliminate the effects of these features. Such issues as the relative ease of misuse of the facility to produce an undeclared product, the usability of declared products in nuclear devices, difficulties in measuring nuclear materials or grouped products with attributes for which proliferation resistance credit was claimed, and the relative technical ease for the host-state to separate plutonium from uranium from a U-Pu grouped product, for example, suggest that claims about significant differences in intrinsic proliferation resistance might be difficult to substantiate. A state capable of designing and building a sensitive facility, including those for which significant intrinsic proliferation resistance is claimed, would also be capable of defeating those intrinsic measures. In reviewing these and other similar statements, it can only be observed that motive and intent of the host state clearly dominate the question of the national proliferation risk question. In this regard, the issue of safeguardability of the process and facility becomes paramount, and has been used as one of the evaluation measures in the Options Study.

However, the availability of SNM is always relevant, since even with clandestine facilities, there must be either SNM or source material to create SNM somewhere in the fuel cycle where a host state could obtain it. For this reason, "material attractiveness" can also be included as a factor in such evaluations.[25-27] As stated in this reference, the development of an unclassified "figure of merit" is discussed which is intended to describe the nuclear explosives utility of a nuclear material within a nuclear fuel cycle, in the context of the other measures considered as part of proliferation resistance, i.e., proliferation technical difficulty, proliferation cost, proliferation time, detection probability, and detection resource efficiency. The results of such material attractiveness evaluations are that both uranium-based and thorium / fissilebased reactors can produce equally attractive materials. According to the figure of merit [25-27], LEU up to $20 \%{ }^{235} \mathrm{U}$ is taken as the reference boundary between attractive and unattractive material. "Reactorgrade" plutonium from uranium, with ${ }^{240} \mathrm{Pu}$ content greater than $24 \%$ is more attractive, while HEU, $93 \%$ ${ }^{235} \mathrm{U}$ and the ${ }^{233} \mathrm{U}$ with up to at least $3200 \mathrm{ppm}$ of ${ }^{232} \mathrm{U}$, typical of the ${ }^{232} \mathrm{U}$ contamination in ${ }^{233} \mathrm{U}$ from the use of a thorium $/{ }^{233} \mathrm{U}$ fuel cycle, are still more and equally attractive. Weapons-grade plutonium, with 
less that $7 \%{ }^{240} \mathrm{Pu}$, i.e., greater than $93 \%{ }^{239} \mathrm{Pu}$, is most attractive. While only an indication, such estimates of material attractiveness allow comparison of one of the aspects of relative proliferation risk associated with the materials potentially available in a nuclear fuel cycle, and indicate those facilities for which a high level of safeguards and security remain essential.

The effectiveness of international safeguards, and the degree to which a particular facility, technology, or process allows efficient implementation of safeguards, i.e., safeguardability, is important to proliferation risk. When comparing various fuel cycle options, alternatives that facilitate implementation of existing safeguards technologies and best practices may be more highly rated, recognizing that current capabilities are all directed towards UNF reprocessing using separation of plutonium, at least from the minor actinides and fission products, since those are the facilities that the IAEA is currently responsible for safeguarding, and that there are also fundamental reasons why the characteristics of separated plutonium may facilitate safeguards implementation, such as very low neutron background. This apparent contradiction between current safeguards capabilities and the apparent perception that separation of plutonium increases proliferation risk (potential security issues aside) is an example of the difficulty facing proliferation risk assessments in the attempt to arrive at unambiguous distinctions between fuel cycle options and technologies using technical characteristics.

\subsubsection{Security}

Unlike proliferation risk, security of nuclear materials is relevant for both nuclear-weapons states and non-nuclear-weapons states. The threat of theft of SNM or other radioactive materials by a Subnational or terrorist group, or the effect of sabotage on civilian nuclear facilities, is important to all civilian nuclear activities. For the INPRO project, the IAEA has stated:[22]

"The IAEA has provided training courses on physical protection of nuclear material and facilities since the 1970's. The overall objective of the IAEA activities in the area of nuclear security can be expressed as follows: To achieve improved worldwide security of nuclear and other radioactive material in use, storage, and transport, and of associated facilities, by supporting Member States in their efforts to establish, maintain, and sustain effective national nuclear security regimes (from the IAEA Nuclear Security Plan 2006-2009). One basic principle has been defined by INPRO in this area [28], asking for an effective and efficient implementation of a physical protection regime for the full life cycle of an INS by the State. The user requirements were developed with due consideration of the Fundamental Principles of Physical Protection contained in the amended Convention on the Physical Protection of Nuclear Material and Facilities."

As a result, the focus of the security issue is first on the types and quantities of SNM and other radioactive materials that would be vulnerable to theft, and second on limiting access to nuclear facilities.

\subsubsection{Implications for an Alternative Fuel Cycle}

As a result of reviewing the numerous documents and studies related to proliferation risk, there are a few observations that have been made in this Options Study.

- Recognizing that national proliferation risk is different from sub-national risk, there is no technological silver bullet that solves the national proliferation risk problem, but there might be technological features of a process or facility that might offer some benefits in addressing subnational risks. The IAEA's ability to safeguard all facilities appears to be of paramount importance to limiting or identifying national proliferation risk, but does not eliminate that risk. The relative safeguardability of alternative fuel cycles and facilities - the degree to which the facilities involved can be effectively safeguarded — should be one basis for comparison of fuel cycle alternatives. 
- The studies emphasize that proliferation risk arises from more than one part of a given nuclear fuel cycle and are not confined to reprocessing facilities. Transportation of both natural and enriched uranium, along with uranium enrichment technology poses a proliferation risk with naturallyoccurring uranium, even if there is no nuclear fuel cycle at all. Neutron irradiation environments, whether reactors or sub-critical external driven systems, all have the capability to produce SNM from either uranium or thorium, with varying levels of efficiency depending on the design. Processing of UNF may enable access to the SNM, either directly or as contained in products. However the separation of plutonium from uranium in a grouped product, for example, must be regarded as well within the technical competence of any nation state capable of designing and building the reprocessing plant that produced the original product. One must look for the "weak links in the chain" across all stages of a given fuel cycle, and where the weakest links are located. Location of the facilities continues to be important. Material attractiveness can be a useful indicator, but must be considered carefully. Assessments of proliferation risk do not necessarily assume diversion of intended products, but often divert UNF, fresh fuel, or impure product material for clandestine processing to obtain weapons usable SNM.

- Security of nuclear materials applies to all nuclear materials, not just SNM, since the adversary goals may not be confined to obtaining a nuclear explosive device, but may also include RDDs. In addition to "gates, guards, and guns," other intrinsic features that deter theft appear to be highly valued, such as the level of difficulty in accessing UNF. The attractiveness of the materials can be a relevant measure, as is the inventory of SNM and other radioactive materials.

- Security of facilities to prevent sabotage or terrorist attack applies to many fuel cycle facilities, and the risks may not be restricted to just nuclear materials if other hazardous industrial chemical are used in one or more parts of the fuel cycle.

In consideration of these observations, there does not appear to by any clearly unambiguous distinction between nuclear fuel cycle options for either proliferation risk or security. Specific technologies may offer advantages or disadvantages, mainly depending on the ability to safeguard the facility in the case of proliferation risk, and on the attractiveness of products that are routinely produced in the case of security.

\subsection{Safety}

Safety of an integrated nuclear fuel cycle includes all activities, although there is certainly a justified focus on reactor and processing facilities due to the concentrated radiological hazard and the potential for accidents to release radioactive materials to the biosphere. A larger view of safety would also include issues related to obtaining the fuel resources, including mining and milling, uranium enrichment, and issues concerning used fuel, including handling, storage, and disposal. However, all of these activities are closely regulated in the U.S., with licensing requirements for such activities. As such, by definition, all facilities and activities will have the required level of safety. However, this is not to say that the effort required to implement all nuclear fuel cycle options is the same, or that all technologies can be implemented to the same level of safety with the same amount of effort.

From the review of facilities and operations associated with the various nuclear fuel cycles and the technologies, there did not appear to be any option that was fundamentally unsafe. At the same time, there are some technology options that have more safety issues than others, with the expectation that additional expense would be incurred to ensure safe implementation of the technology. Similarly, when comparing fuel cycle options and all parts of the fuel cycle are considered, hazards from mining and milling are addressable by fuel cycle options that reduce the need for natural uranium or thorium. However, since such fuel cycle options typically involve recycle, the additional safety concerns for processing would be added. With alternative fuel cycles, the safety risks can be shifted from one part of the fuel cycle to another, and should be considered in evaluating the question of safety. Differences in the 
costs for achieving the required level of safety should be recognized, in that they can indirectly impact safety in the desire to lower the cost of the fuel cycle.

\subsection{Sustainability (Sustainable Nuclear Fuel Cycles)}

In general, sustainability of a nuclear fuel cycle can involve social, economic, environmental, and national security issues related to the use of nuclear energy, the required fuel resources, and resources needed for waste management. The question of available fuel resources is the subject of continued evaluation, with results published in the "Red Book."[29] A related, and more important, question is the ability to produce the fuel resources from the reserves, since the time required from identification of a natural resource until such a resource is being recovered can be a decade or more. In this Options Study, it is assumed that sufficient natural resources exist for any fuel cycle option, and comparisons are made only of the relative need for resources as compared to the once-through fuel cycle.

Other environmental and economic aspects can be addressed at a technical level and be influenced by the choice of nuclear fuel cycle, although the question of adequate fuel supply as a national security issue can also be affected. According to the U.S. Energy Information Agency, the U.S. imported about $86 \%$ of the uranium used for fuel in domestic energy production in 2009.[30] Alternative nuclear fuel cycles can be effective in increasing the utilization of fuel resources, allowing for greater self-dependence of energy supply. Obtaining and producing fuel resources can also have negative environmental impacts, such as land disturbance and $\mathrm{CO}_{2}$ emissions. Increase in fuel utilization with an alternative nuclear fuel cycle will reduce such impacts, but the overall environmental impact of the integrated fuel cycle must always be considered to determine whether there is a net benefit or not.

Similarly, waste disposal requires natural resources for disposal sites. There are environmental impacts in the near term from siting and operating a disposal site, and in the long term from potential releases of radioactive materials. The availability of sufficient land for disposal is a resource issue that can affect sustainability, since all nuclear fuel cycle activities will produce wastes requiring either near-surface burial or deep geologic disposal. Land use and long-term radiological effects are influenced by the waste management issue and are discussed in Section 2.1.

\subsubsection{Uranium-based fuel}

The sustainability of nuclear fuel cycles necessitates the availability of fuel resources for operating the nuclear systems and a viable solution to the issue of nuclear waste management. The use of the fuel for power production requires the presence of a fissile component in the fuel. Uranium is the only naturally occurring element that has a fissile component, with the fissile isotope ${ }^{235} \mathrm{U}$ being about $0.7 \%$ of the total uranium. In the United States, enriched uranium-dioxide fuel is used in the commercial light water reactors (LWRs), necessitating enrichment facilities. While the LWRs are likely to be the major systems for nuclear energy generation in the next century at least, they however do not utilize nuclear fuel material effectively, with only about $0.6 \%$ of the original uranium consumed. Additionally, the conventional LWRs burn less than 5\% of the enriched uranium fuel and hence produce used nuclear fuel (UNF) that has to be disposed of in the once-through fuel cycle. About 20 metric ton per year of UNF is produced by a 1-GWe LWR plant. At the current U.S. nuclear power production level, this implies that a repository of the same legislative capacity as the one planned for Yucca Mountain would have to be built every 30 years of so. This latter issue can be alleviated by using a nuclear system that allows higher fuel burnup.

The production of the uranium fuel requires the mining and milling, conversion and enrichment of the uranium ore. Due to the small concentration of the uranium in nature, the mining and milling is an intensive industrial process, associated with environmental impacts. Additionally, the proliferation of enrichment facility and technology is undesirable because of the potential for misuse. Furthermore, the use of the naturally-occurring uranium will result in a diminishing of this resource, particularly when the 
projected expansion of nuclear technology deployment occurs internationally. These issues point to the need to use the naturally-occurring uranium material effectively. Long-term sustainability of the nuclear industry requires source uranium utilization of the order of $100 \%$ rather than the less than $1 \%$ obtainable with current LWRs. This high utilization of uranium with advanced fuel cycle systems will reduce significantly the environmental impacts of the fuel cycle front-end and could additionally reduce the fuel enrichment needs. It also provides back-end advantages as it reduces the quantity of fuel material to be buried in a disposal site which helps in the effective utilization of repository space. This would increase the time interval between which a new repository would have to be deployed, if more than one is required in the United States.

\subsubsection{Thorium / fissile-based fuel}

Thorium has been considered as an option to uranium-based fuel since the earliest days of the nuclear industry, initially based on considerations of resource utilization (thorium is significantly more plentiful than uranium), and more recently as a result of concerns about proliferation and waste management (e.g., reduced production of plutonium and higher actinides, improved physical properties for potential waste management applications). Since there are no naturally-occurring thorium isotopes that can fission under reactor conditions, thorium is only useful as a resource for breeding new fissile materials, in this case ${ }^{233} \mathrm{U}$. Consequently, an isotope such as ${ }^{233} \mathrm{U},{ }^{235} \mathrm{U}$, or ${ }^{239} \mathrm{Pu}$ must be present in sufficient quantities for the reactor to operate. Thorium can be used in both once-through and recycle options, and in both thermal and fast systems. The thorium-uranium system allows breeding of ${ }^{233} U$ (breeding ratio greater than unity) in both types of systems, although the ability to breed in a thermal spectrum generally requires systems that are significantly different from current commercial LWRs (e.g., tight lattice, reduced power density, molten salt).

Since ${ }^{233} \mathrm{U}$ has similar properties to ${ }^{239} \mathrm{Pu}$, it presents a similar proliferation risk. The high-energy gamma from the daughters of ${ }^{232} \mathrm{U}$ which is also produced may act as a proliferation deterrent if present in sufficient quantities, and requires remote fuel fabrication for a closed thorium cycle. Options have been proposed where sufficient uranium is added to the thorium in the initial fuel composition so that all the ${ }^{233} \mathrm{U}$ is diluted with ${ }^{238} \mathrm{U}$, greatly reducing proliferation concerns, although the addition of uranium leads to the creation of more TRU in the UNF, diminishing the difference between uranium-based and thoriumbased fuel systems in this respect. In considering the thorium-based fuel system, it is essential to recognize the need for fissile material such as ${ }^{233} \mathrm{U}$, enriched uranium or plutonium to operate the reactor.

The environmental and occupational hazards of thorium mining may be more benign than those associated with uranium due to the less hazardous decay products associated with thorium. Since $\mathrm{ThO}_{2}$ is relatively inert, and thorium/fissile-based fuel cycles use $\mathrm{ThO}_{2}$ for fuel, long term interim storage and permanent disposal in a repository of used $\mathrm{ThO}_{2}$-based fuel are simpler for some repository environments making it well-suited for utilization in a once-through cycle. On the other hand, the same chemical stability makes reprocessing of thorium-based fuels more complicated.

Thorium-based fuels can be utilized in any reactor/nuclear system in open and closed cycles. Generally, the ${ }^{233} \mathrm{U}$ is utilized most effectively in thermal/epi-thermal systems (e.g., LWRs, HWRs, HTGRs, and MSRs). Many studies have been performed for once-through implementation of thorium in commercial PWRs and show that improvements over conventional uranium-based fuels are possible (factors of approximately 2-5 reductions in plutonium production and waste). Studies have shown that a selfsustaining ${ }^{233} \mathrm{U} / \mathrm{Th}$ cycle can not be achieved in a standard commercial PWR without design compromises (e.g., reduced power density). Therefore, breeding of ${ }^{233} \mathrm{U}$ for a closed ${ }^{233} \mathrm{U} / \mathrm{Th}$ cycle would require "prebreeders" (e.g., EDS, several commercial LWRs to support a single LWR), or blankets in a fast-spectrum reactor, an MSR, or specially designed LWRs. The fuel cycle/reactor can be tailored to enhance the ${ }^{232} \mathrm{U}$ content to increase proliferation resistance. 
Implementation of thorium-based fuels and the thorium cycle offer a number of potential benefits relative to the conventional uranium fuel cycle and uranium-based fuels. These are most evident in the classic "true thorium cycle $-{ }^{233} \mathrm{U} / \mathrm{Th}$ " where the production of higher actinides is significantly reduced, and the nuclear and physical characteristics of ${ }^{233} \mathrm{U} / \mathrm{Th}$ can be utilized to greatest advantage, although it must be recognized that this is directly comparable to the ${ }^{239} \mathrm{Pu} / \mathrm{U}$ approach in terms of proliferation risk. There are also potential operational and safety benefits with thorium-based fuels (e.g., higher burnup, improved void coefficient in a sodium fast reactor). Issues associated with potential large-scale utilization of the Th cycle in the U.S. include:

- Development of a new infrastructure (fuel fabrication, transportation, storage, etc.), and development of a fuel separation infrastructure in recycle scenarios to extract the ${ }^{233} \mathrm{U}$ or other actinides to address potential use scenarios (e.g., burning plutonium and other TRU elements), which introduces cost, licensing, and RD\&D penalties.

- If the objective is a complete avoidance of the need for uranium and uranium enrichment, sufficient quantities of ${ }^{233} \mathrm{U}$ for the ${ }^{233} \mathrm{U} / \mathrm{Th}$ variant need to be produced requiring a "pre-breeding"/breeder infrastructure.

\subsubsection{Technical implications for the fuel cycle}

The requirement to more effectively utilize uranium and thorium discussed above, necessitates that new fissile nuclides be created from the source uranium or thorium in nuclear systems. Advanced fuel cycle concepts have been considered for this purpose. Typically, in one form or the other, the breed and burn $(\mathrm{B} \& \mathrm{~B})$ of fissile nuclides is envisaged. This approach can be used in either once-through nuclear systems involving no fuel separations or in recycle systems in which fuel separations is necessary.

The new fissile nuclides are created by neutron capture (rather than fission) in fertile nuclides in the fuel (e.g., in ${ }^{238} \mathrm{U}$ or ${ }^{232} \mathrm{Th}$ creating ${ }^{239} \mathrm{Pu}$ or ${ }^{233} \mathrm{U}$, respectively). Various reactor types and designs have been considered for this purpose. For a sustainable nuclear system it has generally been found necessary to use a reactor design having a fissile conversion ratio greater than or about 1, implying a system in which more fissile material is produced than consumed. For uranium-based systems it has been found that this high conversion (breeding when $\mathrm{CR}>1$ ) is more favorably accomplished in fast reactor systems. Consequently, both once-through and recycle systems using uranium-based fuels in the B\&B concept have typically considered a fast reactor design. A fast reactor could also be used with thorium-based $\left(\mathrm{Th} /{ }^{233} \mathrm{U}\right)$ fuels, though its breeding performance is less than that of a U-Pu fuel system.

Thermal reactors have been considered for breeding with thorium-based fuel (particularly $\mathrm{Th} /{ }^{233} \mathrm{U}$ ), but cannot be used practically for uranium-based fuels. Molten salt reactors and water-cooled reactors [31-33] are two systems which could be used for this purpose, though the breeding process appears easier from a reactor-physics viewpoint for the former reactor system, because of the continuous removal of neutron poisons (fission products) and the possibility to minimize control-rod absorber requirements.

For externally-driven systems, both thermal and fast spectrum blankets can be utilized to achieve high utilization. Assuming that the external source provides the bulk of the neutron flux (and not from neutron multiplication in the blanket), a thermal spectrum blanket might be more attractive than a fast spectrum blanket, due to the higher neutron cross sections in the thermal energy range. If neutron multiplication in the blanket provides the bulk of the neutrons, then a fast spectrum system might be of interest because of its favorable neutron balance. 


\subsection{Economics}

The economics of nuclear power, and the fuel cycle in general, have been a primary issue that is raised as both a barrier for the re-establishment of growth in the nuclear enterprise or the adoption of an alternative nuclear fuel cycle, especially if the fuel cycle is more complex as would occur with the recycle option.

Nuclear fuel cycle facilities, including reactors and processing plants, are capital-cost intensive with costs exceeding several billion dollars. These costs, in many cases, are comparable to the total market capitalization value of the private sector electric utilities that would have to finance and build these facilities, resulting in a single new investment representing an extreme investment risk, i.e., costing as much or more than the current value of the entire utility. Furthermore, a major factor related to economics is the large uncertainties in the costs of the nuclear facilities based on experience with the deployment of the most recent nuclear reactors constructed in the U.S., a lack of demonstrated experience in meeting construction schedules, and the need to show that new licensing processes can reduce the regulatory uncertainty that has resulted in delays in the past. This is combined with the uncertainty in the revenue generation of the new nuclear plants, given the electricity market price impact of substantial new supply, the large variations in the cost of competing energy sources (primarily natural gas), strong government incentives supporting alternative energy sources (such as tax credits for wind and solar energy), and uncertainty about the time-frame for implementing carbon control measures that would increase the electricity production price from existing supply, such as cap-and-trade or carbon taxes. In recognition of these issues, the U.S. government is supporting near-term deployment of nuclear reactors and fuel cycle facilities through loan guarantee programs, with one loan guarantee in place for Georgia Power's Vogtle nuclear reactors (2 units, \$8B loan guarantee [34]) and one fuel cycle facility (AREVA Eagle Rock enrichment facility with a \$2B loan guarantee [35]). Competition between competing facility proposals is complicating efforts to move forward, where the limited funding available in loan guarantees is putting the U.S. Government in a position of having to choose among the proposals, rather than being able to support the market in general.

However, it is very important to note that while the costs associated with large nuclear power production facilities is substantial (as it is with other forms of electricity generation), with a typical $1 \mathrm{GWe}$ LWR having a cost on the order of $\$ 4-5 \mathrm{~B}$, the revenue created by the operation of the nuclear plants in producing electricity is also very large. The same 1 GWe LWR produces revenue from the sale of electricity of approximately $\$ 750 \mathrm{M} / \mathrm{yr}$ (based on an average U.S. retail cost of electricity in 2010 of 9.67 cents/kWh [36]), or $\$ 45 \mathrm{~B}$ over the expected 60 year lifetime of the reactor. Similarly, while the latest total life-cycle cost of the proposed Yucca Mountain repository (including transportation) was approaching \$100B[37], the revenue generated from the production of electricity by the UNF that would be placed in the repository is greater than $\$ 5 \mathrm{~T}$ (based on 70,000 MTHM UNF, $45 \mathrm{GWd} / \mathrm{MTHM}, 9.67$ cents/kWh).

\subsubsection{Uncertainties in the Cost of Nuclear Facilities}

A key issue in assessing the economics of all nuclear power and fuel cycle concepts is the associated uncertainty in the capital cost of the nuclear facilities. This is reflected in the economics evaluation criteria that were outlined in the Phase I Options study report. These criteria include:

- Similarity to existing infrastructure

- Capital at risk

- Technical maturity

- Technical risk

- Development time 
- Life-cycle costs

Arguably, the first five of these evaluation criteria are measures of economic risk, with life-cycle costs reflecting the actual financial cost. The combination of high capital cost and large uncertainties in schedule from events both internal and external to the design and construction project results in significant financial risk that would not be present if the technology had much lower cost.

An indication of the uncertainty in the cost of nuclear power can be provided by reviewing the available cost data for light water reactors (LWRs), which are by far the most widely deployed nuclear facilities and for which there are significant plans for deployment in the U.S. within the next decade. An evaluation of the costs of LWRs has been performed [38], as well as other studies cited in the Phase I Options Study report, in which a review of the historical and projected costs is performed to provide a range of costs (low, nominal, and high). In the latest edition of the cost database, the total capital cost including financing (LWR, in terms of cost per unit electricity production for an "Nth of a kind" plant) is shown in Figure 8. In comparison to the nominal overnight cost, the low and high costs vary by a range of almost $\pm 40 \%$. Further information is provided in the report for specific plants in terms of an "all-in" (capital + financing). These reported costs show similar cost variations of approximately $40 \%$. The variations in these all-in costs include both variations in the over-night capital cost and in the financing rate that can be obtained and therefore are sensitive to the time that it takes to construct the facility (an evaluation metric). This data shows that even for the most widely deployed nuclear technology, projected costs have a relatively wide degree of variation.

In the case of more advanced nuclear technology that has not been widely deployed, the expected variations are expected to be even larger. For example, the overnight capital cost range provided in AFCI cost data base for fast reactors is $\$ 3,000, \$ 4,200$ and $\$ 7,000 / \mathrm{kWe}$ for the low, nominal and high cost. So while in comparison to the LWR costs the nominal cost is $20 \%$ higher, but based on the range provided, the range of costs indicate that under certain conditions a fast reactor cost could be less than that of an LWR.

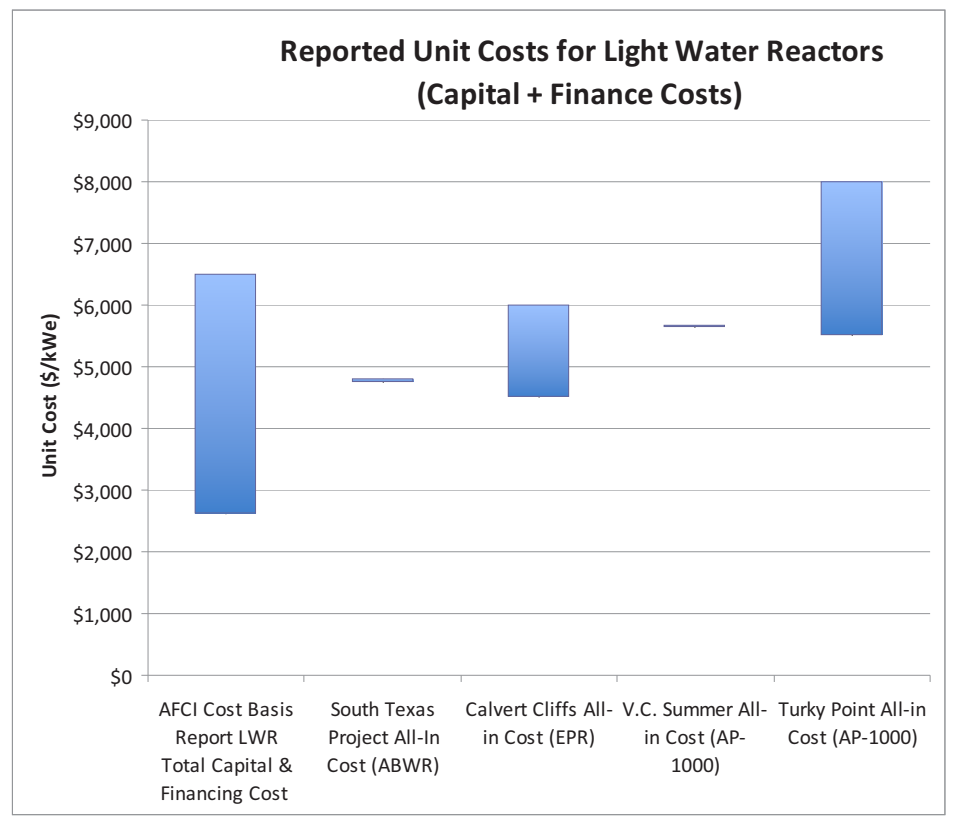

Figure 8. Examples of the reported cost ranges for light water reactors including recommended values from AFCI cost basis report and reported values for three near-term LWR reactor deployments [38] 


\subsubsection{Uncertainties in the Cost of Nuclear Fuel Cycles}

In order to evaluate whether there are significant difference in costs for the various nuclear fuel cycles, the cost differential between the options must be significantly larger than the uncertainties in the costs. If the uncertainties are not considered, as Figure 8 illustrates, a comparison of the nominal costs for nuclear fuel cycles can lead to unsubstantiated conclusions. The above considerations of the uncertainties for the cost of nuclear facilities (as well as uncertainties in fuel and operation and maintenance costs) can be incorporated into the cost analysis of the total cost of nuclear fuel cycles that can provide a cost comparison of options that reflect these uncertainties.

As part of the AFCI program, an analysis of the costs of several fuel cycle options was completed. A once-through fuel cycle using an LWR, a recycle system that only used fast reactors (called a "one tier system in references), and a recycle system that included LWRs in a single recycle mode with MOX, followed by the LWR MOX UNF being processed for recycle in fast reactors were evaluated. Costs of each fuel cycle was calculated including uncertainties due to variations in reactor capital costs, uranium prices, recycle facility costs, variation in waste form costs, and repository costs to obtain cost probability distributions.[39] Figure 9 shows these distributions for each of these three fuel cycles. Based on the mean values (indicated by the vertical lines in the figure) the once through fuel cycle cost is approximately $47 \$ / \mathrm{MWh}$, while the mean cost for both recycle cases are the same (the cost distributions fully overlap) with a value of $53 \$ / \mathrm{MWh}$. Therefore, the recycle cases have a mean cost that is approximately $6 \$ \mathrm{MWh}$, or $10 \%$ more than the once-through case. This is generally expected given the increased cost of the fast reactors in comparison to LWRs, and that recycle involves a more complex nuclear fuel cycle with additional facilities. However, both of the distributions have a cost distribution range that is much larger than this difference and, in fact, overlap significantly. Therefore, in terms of the wide cost distributions, it is not clear that one can consider the $10 \%$ larger mean estimated cost for the recycle case a significant cost difference from the LWR once-through case.

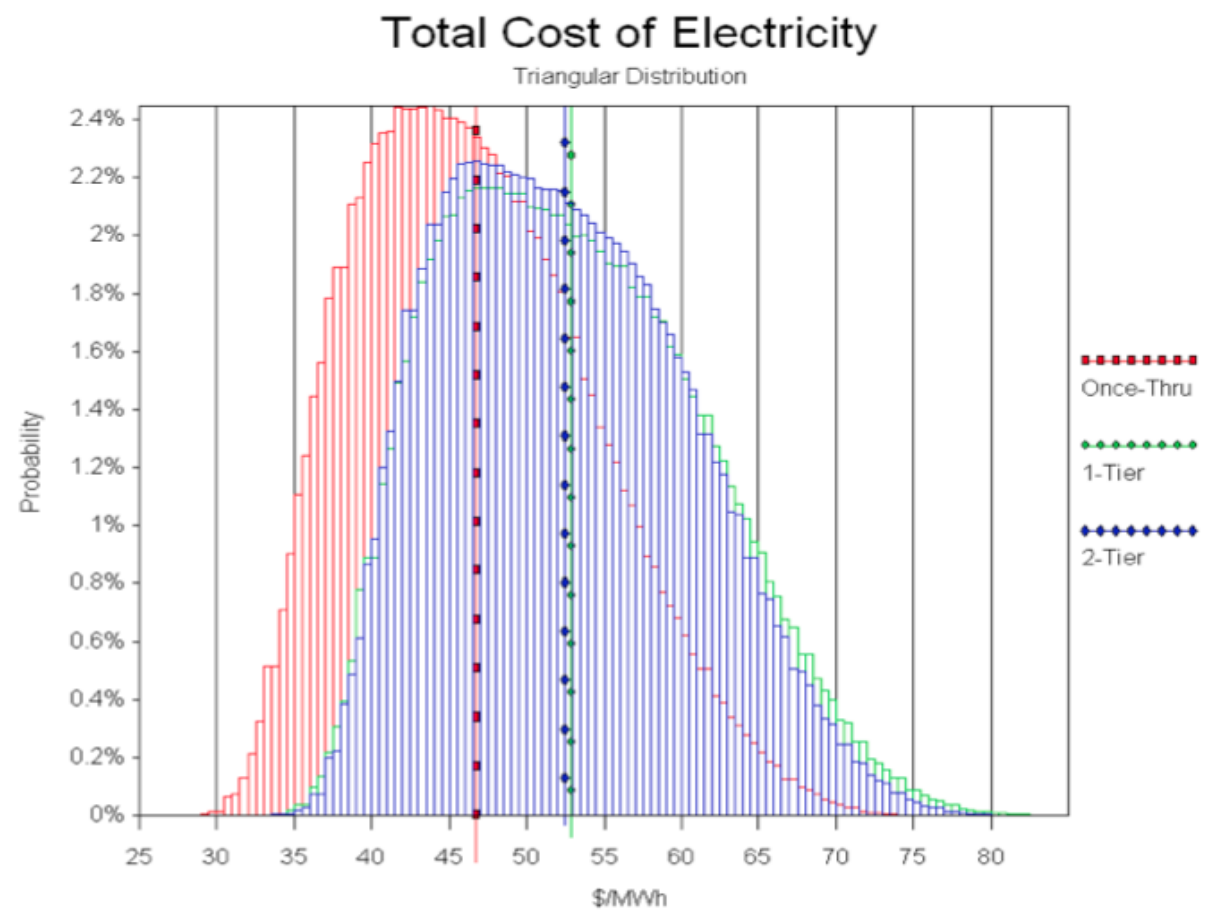

Figure 9. Cost distributions for a once-through LWR fuel cycle, a recycle fuel cycle with a fast reactor ("1 Tier"), and a recycle fuel cycle with combined once-through LWR and recycle fast reactor ("2 Tier") [39] 


\subsubsection{Economics Implications for the Fuel Cycle}

The costs of nuclear facilities are very large and can be prohibitive for private industry and utilities to finance given the magnitude of the costs in comparison to the size of the private companies. However, this large cost is balanced by a large revenue stream should the facilities be successfully deployed and operated. Therefore, given this balance of both large costs and revenues, the profitability of the nuclear enterprise lies in the uncertainties in the costs and profits.

Based on the above discussion and demonstration of the significance of cost uncertainties, in general there are many factors that can impact the cost of deployment and operation of the fuel cycles such that in most cases the differences in costs of particular fuel cycles cannot be demonstrated to be significantly different. Further, estimated reduction in costs for some of the proposed advanced fuel cycles appears to be even more uncertain given their relatively low technical development and demonstration. As a result, it does not appear that one can make definitive statements about a significant cost difference, either more or less expensive, compared to the once-through LWR fuel cycle. However, this observation would imply that one may be able to consider alternative nuclear fuel cycles without incurring a significant cost penalty, although within any fuel cycle option, there are certainly technology options that are expected to be significantly more costly due to obvious complexity or other features.

\section{NUCLEAR FUEL CYCLE OPTIONS}

Both advanced once-through and recycle systems have been considered for their ability to address the issues with nuclear power associated with the LWR once-through fuel cycle currently used in the United States, including uranium-based fuel and thorium/fissile-based fuel. The performance of critical systems (reactors) and externally driven systems has been reviewed. The basic question is under what circumstances recycle would logically be considered, since it involves a more complex nuclear power infrastructure than once-through approaches.

\subsection{Once-through and Recycle}

Based on the discussions of the issues in Chapter 2, there are a number of aspects to consider when comparing the attributes of once-through and. recycle systems. In examining this question, it is important to consider what the fundamental advantages and limitations are for each approach.

\section{Waste Management - Waste Disposal Sustainability and Environmental Impact}

Nuclear fuel can only be used as long there is sufficient fissile material to support the nuclear reaction, considering that the fission product materials that absorb neutrons, "poisons," build up as the fuel is consumed. Since these fission products are not removed with a once-through fuel cycle, the fission process eventually stops, limiting the use of the fuel. The UNF is then disposed using deep geologic disposal. As a consequence, any use of fuel in a reactor with a once-through fuel cycle requires that a relatively large quantity of nuclear fuel be provided for power production, and that all of the UNF be buried at a geologic disposal site. Typically, in a once-through system the fission products build nearly linearly with fuel burnup and actinide content approaches (but does not reach) a quasi-equilibrium level with ongoing isotopic evolution with increasing burnup. This combination limits the potential waste management benefit for once-through systems to only moderate differences. An exception to this could be an externally driven system with sufficient neutrons to approach nearly complete burnup, where the final actinide content could be lowered.

With recycle, actinides are typically separated and reused in fuel, producing further energy and fission products. By so doing, on the basis of energy generated, the amount of highly hazardous material per unit of energy produced that would need to be buried using geologic disposal can be greatly reduced. 
This reduction could be used to greatly lower the inventory to be disposed in a given repository site, reducing potential releases and making uncertainties less important. Alternatively, the greatly lower decay heat and radionuclide inventory could permit a disposal site to effectively accept high-level waste associated with a near 100-fold increase in energy generation. This would potentially significantly reduce the need to establish new disposal sites on a regular basis after every few decades of nuclear operations. However, the fuel recycle being practiced in Europe does not give this full benefit of recycling, as the used mixed oxide (MOX) fuel has to be buried in disposal site. Finally, it is noted that even with actinide recycle where all UNF is processed, there would still be need for a disposal site for the burial of the fission products and the fuel material losses during reprocessing.

\section{Proliferation Risk and Security}

Fuel recycle could be used to reduce significantly the enrichment requirements in the fuel cycle. In truly sustainable systems, in which fissile material is created to balance fissile material depleted, it is possible to ultimately forgo the need for enrichment facilities by creating more fissile material and using the surplus material to fuel new nuclear systems. The trade-off, however, is the reprocessing of UNF in the fuel cycle and the potential diversion of SNM from the fuel cycle if appropriate safeguards are not applied.

The used nuclear fuel in a once-through fuel cycle contains SNM, either that originally in the fresh fuel or that produced during the irradiation process in a nuclear reactor. Assuming that the UNF is disposed in a geological repository, the SNM content of the UNF would be initially self-protected by the high radiation field caused by the presence of highly radioactive short-lived radionuclides. However, this radiation field will decrease with time, and one concern is that the repository might become a "mine" for SNM, unless it is under essentially permanent safeguards forever. Similarly, extended storage of UNF will also make the SNM content more accessible with time. A recycle approach can be used to alleviate this problem, as the SNM could be recovered and re-used, thereby greatly limiting the quantity of SNM send to a repository to only that lost during the reprocessing stage. In this case, a high recovery factor of the SNM during the reprocessing stage would limit the losses to waste.

The ability to safeguard SNM in a nuclear fuel cycle is an essential part of limiting proliferation risk. Effective implementation of safeguards can be enabled by characteristics of the technologies and the facilities in which the technology is implemented. Fuel cycle technologies that can use existing safeguards instrumentation and approaches, and that can take advantage of current "best practices" may be perceived as having lower proliferation risk. In summary, fuel cycle technology options that facilitate effective implementation of safeguards would contribute to lower proliferation risk.

\section{Fuel Utilization - Resource Sustainability and Environmental Impact}

The fuel burnup in a once-through approach using reactors can be limited by the build-up of fission products, which could limit the utilization of fuel resources. However, the used fuel has fissile material that could be re-used in the fuel cycle, and with the separation and removal of the fission products by processing, the fissile materials can be recycled to produce additional power.

Higher fuel utilization than can be achieved with conventional LWRs is theoretically possible with fast reactors in a once-through fuel cycle, as in the case of the "breed and burn" reactor systems currently being proposed (e.g., the traveling-wave class of reactors), where the reactor is designed to create new fissile materials at the same time that fissile materials are fissioned. Such reactors are also limited by the build-up of fission products. For this reason, some of these concepts that were originally proposing a once-through fuel cycle are now contemplating the use of recycle to extend fuel utilization. 
Similarly, it is conceptually easy to imagine a once-through nuclear system driven by an external source of neutrons, as can be provided by fusion-fission hybrid systems or an accelerator with a spallation neutron source. Such a system could in principle be used to achieve very high fuel burnup, depending on the design. Fuel performance and integrity considerations make this high fuel utilization quite unlikely in the foreseeable future, as materials do not exist currently that can withstand the much higher neutron fluence. Its future application would require revolutionary developments in advanced materials technology.

Given the limitations posed by the presence of fission products and the lack of appropriate fuel and structural materials, recycle is the only option for increasing the utilization of fuel. In this case, the used nuclear fuel is reprocessed to recover the useful fissile materials that can be re-used in nuclear systems. It is evident that with recycle in critical or externally-driven nuclear systems, high fuel utilization (greater than $99 \%$ ) could be achieved in the fuel cycle if the system were designed with that as an objective. In such systems, only nuclear fuel losses during fuel separations and fission products will be sent to a disposal site.

It should be noted that thorium can only be effectively used in critical systems with a recycle approach. Once-through use of thorium requires enriched uranium to provide the fissile material, ${ }^{235} \mathrm{U}$, until some of the thorium has been converted to new fissile material, ${ }^{233} \mathrm{U}$. However, in a once-through approach, simultaneous buildup of fission products competes with the creation of the new fissile material, limiting use of the fuel. If the reactor is designed for efficient creation of new fissile, thorium along with uranium can be used with a recycle approach to achieve very high consumption of the thorium.

\subsection{Choices that Make a "Significant Difference"}

In consideration of the technical implications for the fuel cycles as summarized in Chapter 2, and the entire range of once-through and recycle fuel cycle options, it is possible to identify those fuel cycle options where a significant difference can be made to the issues with nuclear power. The general categories of fuel cycle options and the best attainable performance for specific options within each category are presented in Tables 1 and 2 for uranium-based and thorium/fissile-based fuel. Both oncethrough and recycle options are listed, for critical and sub-critical systems, and for thermal and fast neutron irradiation. Also listed on the table is an entry for non-neutron irradiation possibilities, but review of available literature did not provide sufficient information to evaluate the potential of such systems.

It is essential to understand the meaning and implications of "best attainable performance" in the tables. Taking the examples of the recycle options for waste management, only those fuel cycle options that do not dispose of UNF are capable of providing significant benefit. Other approaches, where recycle is used one or more times but eventually the UNF is disposed, do not have the capability to provide a significant benefit, even though all of the other characteristics of the fuel cycle would place it in the same category. The same is true for the sustainability issue, although the issue is more complex since sustainability reflects the use of natural resources for both obtaining fuel and for having sufficient disposal space. For the fuel resource issue, only those fuel cycles that are able to efficiently breed enough fissile material to compensate for the fissile material being used to produce power will be able to provide a significant benefit in extending fuel resources. This is not possible with the use of uranium in thermal reactors, but it is easily done in fast reactors. However, thermal recycle of actinides with uranium-based fuel is capable of significantly reducing the needed disposal space. So, on Table 1, the fuel cycle options providing a significant difference to sustainability are aimed at disposal resources, while in Table 2, the fuel cycle options providing a significant difference both extend resources and reduce the needed disposal space. It is important to consider the specific fuel cycle options in all cases, but the Tables identify where significant benefits may be obtained. 
As can be seen from the Tables, the fuel cycle option categories that have one or more specific fuel cycle options that are capable of providing significant benefits to the issues associated with nuclear power are identified. It should be noted that the fuel cycle options are the same for Table 1 and Table 2, reflecting the ability to use either a uranium-based or thorium/fissile-based system. However, the specific fuel cycle option within each category is not necessarily the same due to the differences in uranium and thorium with neutron irradiation, in that thorium is able to more effectively breed new fissile, ${ }^{233} \mathrm{U}$, in a thermal system than uranium, although the breeding potential is smaller than that for uranium in a fast neutron spectrum. To illustrate the types of specific fuel cycle options that could be considered, the following sections provide examples for each of the fuel cycle option categories.

\section{Waste Management - Waste Disposal Sustainability and Environmental Impact}

Options to significantly improve nuclear waste management focus on those materials requiring deep geologic disposal, and potential options are generally based on greatly reducing the waste inventory of the radionuclides important for radiation exposure and decay heat. While the specific approach that may benefit undisturbed repository performance will be dependent on the engineered repository and the specific geologic environment, actinide elements can be important for both radiation exposure and decay heat, and long-lived fission products can be important for radiation exposure. Whether a benefit would be obtained or not for a specific deep geologic disposal option cannot be known until both a host environment and repository design are known, and even then the resulting analyses are at least partly subjective due to the assumptions that need to be made. Typically however, for undisturbed conditions, important fuel cycle waste characteristics include at least decay heat limitation, and may include fission product and actinide inventory. For disturbed conditions, both actinides and fission product inventories are likely to be important.

For each of the uranium based fuel cycle options in Table 1 that indicate potential for significant improvement in waste management (those shaded bright green in the Waste Management column), example fuel cycle technologies are provided below. These suggestions may not be the only technology combinations in that category, and may not be the only ones that might provide significant benefit, but are offered as representatives of the category.

- Once-through - Subcritical - fast.

- Fusion-fission hybrid: fuel irradiated to very high burnup where the actinide content is burned down to substantially reduced levels prior to fuel disposal.

- ADS: fuel irradiated to very high burnup where the actinide content is burned down to substantially reduced levels prior to fuel disposal.

- Recycle: Critical - thermal. Examples based on lower decay heat and lower actinide content include

- $\quad$ LWR - CORAIL (U-based fuel with recycle of Pu, Np, Am with separate Cm decay)

- $\quad$ LWR - CONFU (U-based fuel with recycle of $\mathrm{Pu}, \mathrm{Np}$, Am w/separate $\mathrm{Cm}$ decay)

- $\quad \mathrm{LWR}$ - Pu, Np recycle with Am, Cm decay storage and recycle)

- $\quad$ HTGR heterogeneous fuel (U-based fuel with $\mathrm{Pu}, \mathrm{Np}, \mathrm{Am}$, recycle, $\mathrm{Cm}$ decay) possibly in connection with deep burn

- Other thermal recycle approaches where $\mathrm{Pu}, \mathrm{Np}, \mathrm{Am}$, and $\mathrm{Cm}$ are separated from materials destined for deep geologic disposal

- Recycle: Critical - fast

- Fast neutron irradiation

- Sodium-cooled fast reactor with metal fuel and electrochemical separations and actinide recycle with processing of all UNF 


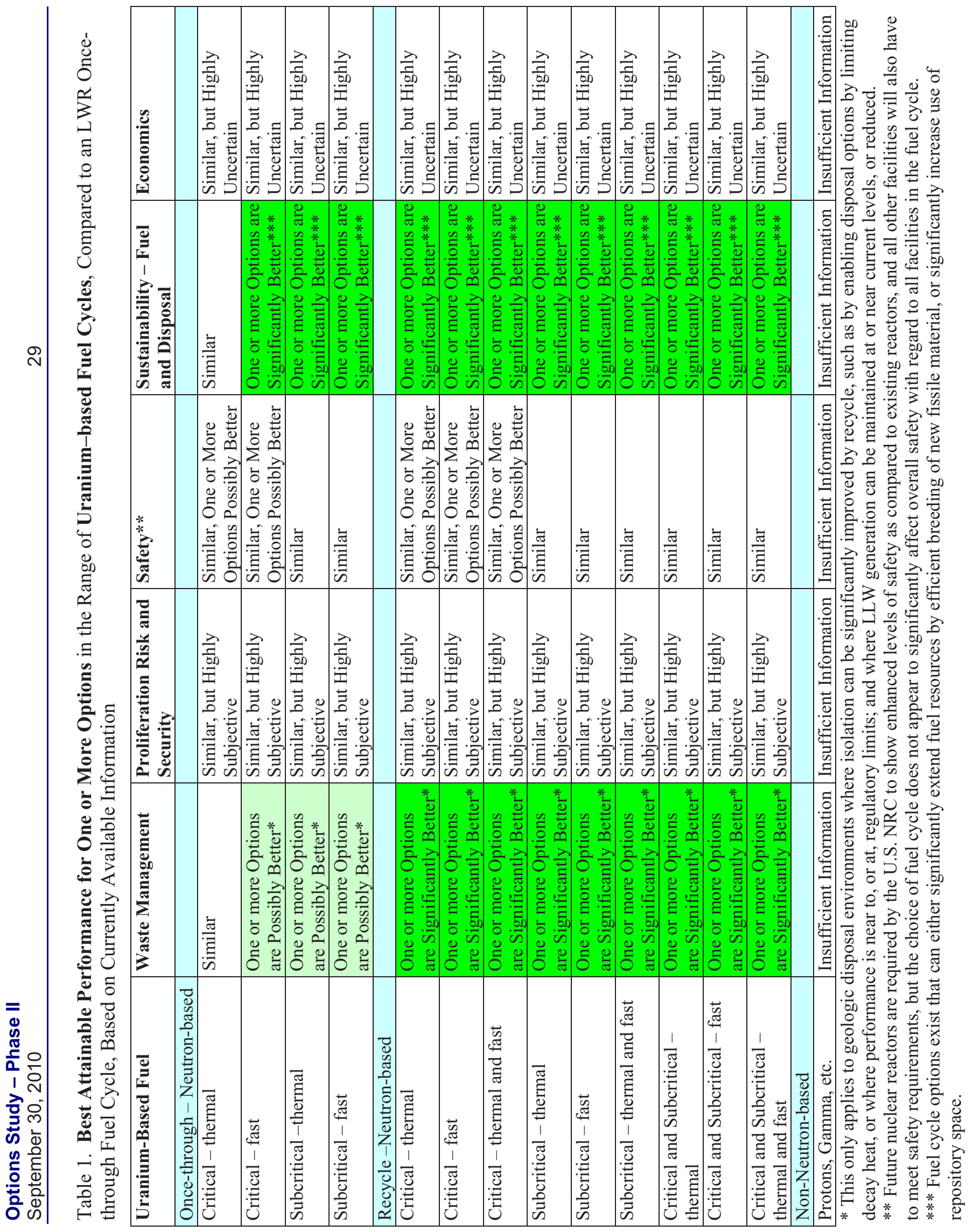




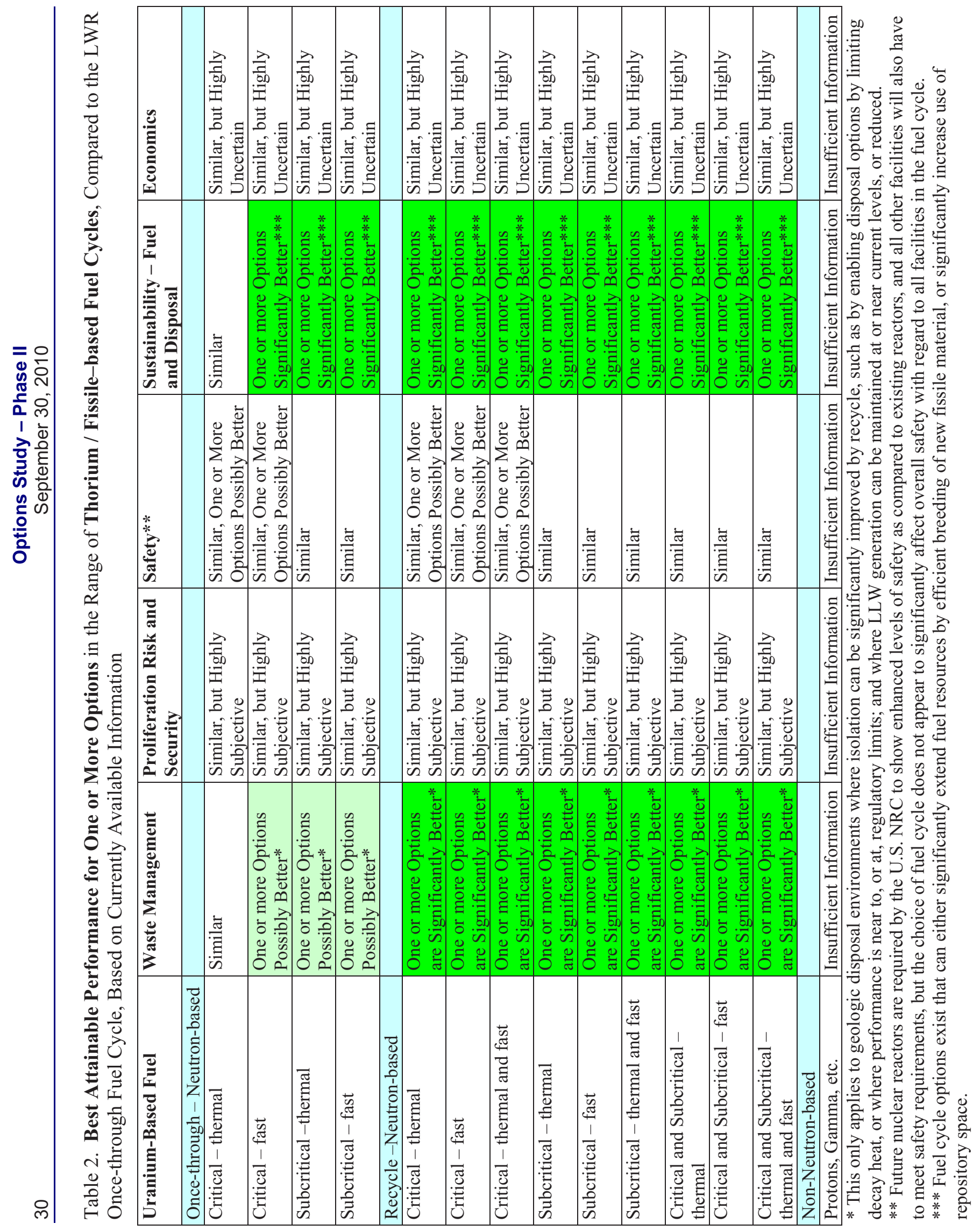


- Sodium-cooled fast reactor with oxide fuel and aqueous separations and actinide recycle with processing of all UNF

- Any other fast neutron reactor (LFR, GFR, ...) with processing of all UNF

- Fast reactors with only $\mathrm{Pu}$ or $\mathrm{Pu}+\mathrm{Np}$ recycle may achieve lower, but still significant, waste management benefits due to reduction in some actinides and not others

- Fast reactor systems with actinide recycle and transmutation of specific fission products may achieve greater waste management benefits via reduction in problematic long-lived fission products as well as actinide reduction, depending on the geologic disposal environment

- Recycle: Critical - thermal and fast

- $\quad$ LWR + FR - Initial fuel use in LWRs and subsequent actinide recycle in fast reactors with processing of all UNF.

- Variations could recycle Pu one or more times in LWRs prior to FR use.

- Any other combination of thermal reactors and subsequent recycle of actinides in fast reactors with processing of all UNF.

- $\quad$ (LWR/FR, HWR/FR, /HTGR/FR, ... with actinide recycle and processing all UNF)

- Combination of thermal and fast reactor systems with actinide recycle and transmutation of specific fission products targets may achieve greater waste management benefits via reduction in problematic long-lived fission products as well as actinide reduction

- Recycle: Subcritical - thermal

- Any thermal-spectrum externally-driven system, such as an FFH or ADS with recycle of actinides and processing of all UNF.

- Recycle: Subcritical - fast

- Any fast-spectrum externally-driven system, such as FFH or ADS, with recycle of actinides and processing of all UNF.

- Recycle: Subcritical - thermal and fast

- Any combination of thermal- and fast-spectrum externally-driven systems with recycle of actinides and processing of all UNF.

- Recycle: Critical and Subcritical - thermal

- Any combination of thermal reactors and FFH or ADS with actinide recycle and processing of all UNF.

- LWRs using uranium-based fuel and ADS for transmutation of actinides with processing of all UNF

- Recycle: Critical and Subcritical - fast

- Any combination of fast spectrum reactors and FFH or ADS with actinide recycle and processing of all UNF

- Sodium-cooled fast reactor with ADS actinide recycle. Option for select fission product transmutation also possible.

- Recycle: Critical and Subcritical - thermal and fast

- Any combination of thermal-spectrum and/or fast-spectrum reactors and FFH or ADS with actinide recycle and processing of all UNF.

- LWR with fast-spectrum ADS actinide burner with processing of all UNF. Option for select fission product transmutation also possible 
For the Thorium based systems in Table 2, a parallel set of fuel cycles exists with recycle of primarily

${ }^{233} \mathrm{U}$ and limited transuranics inventories. Externally-driven subcritical systems are more likely to be used to produce fissile ${ }^{233} \mathrm{U}$ rather than to transmute actinides. There are fewer examples of continuous recycle Th based options than $\mathrm{U}$ based. The two most commonly considered are:

- Recycle: Critical - thermal.

- $\quad$ MSR - Th-salt fueled reactor with continuous processing of the fluid fuel to remove fission products for disposal. Most actinides remain in the system until they fission.

- $\quad$ LWBR - LWR specifically designed to breed ${ }^{233} U$ from Thorium with processing of all UNF.

There are also hybrid Th-U systems that share characteristics of those discussed above.

While there are typically fewer transuranic isotopes in the Th-fissile based fuel cycle, there can be significant radiotoxicity in the thorium decay chain products. To reduce long-term radiotoxicity for thorium systems, it becomes useful to attempt near-complete utilization of the thorium resource with actinide recycle and processing of all UNF.

\section{Fuel Utilization - Resource Sustainability and Environmental Impact}

A sustainable nuclear system must have a reliable nuclear fuel source and a strategy for waste management. Fissile material required for generating nuclear power can be obtained in one of two ways: (1) the enrichment of the source uranium in its ${ }^{235} \mathrm{U}$ content, as practiced in the current U.S. LWR fuel cycle, (2) the recovery/utilization of fissile material (such as ${ }^{233} \mathrm{U},{ }^{239} \mathrm{Pu}$, and ${ }^{241} \mathrm{Pu}$ ) created in the nuclear system as a result of neutron interaction with fertile fuel (e.g. uranium and thorium). Thus, fuel material sustainability can be assured by two primary approaches:

- Fuel exploration can be used to find and accumulate uranium resources consistent with the expected needs of the deployed advanced fuel cycle architecture. This entails appropriate timing of the development of facilities needed for exploiting the natural resources (e.g., mining, milling and enrichment facilities).

- The utilization of the nuclear fuel is increased from the current $\sim 0.6 \%$ source uranium utilization in LWRs to greater than $95 \%$ in advanced fuel cycles. This higher utilization can be achieved using nuclear systems designed for that purpose. As previously noted these could be either once-through or recycle nuclear systems.

The goal of higher nuclear fuel utilization can be achieved in a once-through fuel cycle by increasing significantly the fuel consumption. Increasing just the fuel enrichment to high values to support high burnup is insufficient to increase the fuel utilization. This is because of the enormous uranium tailing that results from the enrichment process. Unless this tailing could be consumed in the fuel cycle, the overall fuel utilization would be less than $1 \%$, even if the enriched uranium fuel is completely burned. An effective approach is to use the breed and burn concept in which new fissile materials are created and consumed in the nuclear system. Some once-through fuel cycle systems recently considered for high fuel utilization include the fast mixed spectrum reactor system (FMSR) by BNL, the CANDLE system proposed by the Tokyo Institute of Technology, and the sustainable sodium-cooled fast reactor (SSFR) proposed by ANL. Assuming the availability of advanced fuel materials, these systems can obtain fuel utilization of the order of $30 \%$, which is about a 50 -fold increase compared to that of the existing LWRs.

Externally-driven systems such as the LIFE fusion-fission hybrid (FFH) concept have also been considered for high fuel utilization in a once-through nuclear fuel cycle. Accelerator-driven systems could be similarly used. Assuming the availability of sufficient excess neutrons from the fusion component, natural uranium or thorium could be irradiated first to create fissile material and then the material burned for power generation, without necessarily removing the fuel from the FFH system. 
Relative to the conventional LWRs, some small gains in fuel utilization and reduction of UNF quantity can be achieved by using advanced systems with high thermal efficiency in converting thermal power to electric power, but the corresponding economic impact may be viewed as significant. Systems such as fast reactors (FRs) and very high temperature reactors (VHTRs) which can have thermal efficiencies close to $40 \%$ and $50 \%$, respectively, can be used for this purpose; LWRs have values of about $33 \%$. This corresponds to increases in fuel utilization or reduction of UNF inventory of about $20 \%$ and $50 \%$, in FR and VHTR, respectively, directly from the higher thermal efficiencies.

Fuel performance considerations might however limit the level of fuel consumption that is practical in a once-through system. Continuous recycling of UNF could be used to increase the fuel utilization, as an alternative approach. In this case, UNF is reprocessed to recover all heavy metal material that is then recycled into the nuclear system for further irradiation. Both solid fuel and liquid fuel concepts have been considered for this purpose. Traditionally with solid uranium-based fuels, fast spectrum systems are more attractive due their better neutron economy. The continuous recycle fast-spectrum system (reactors and externally-driven systems) can be used. For thorium fuel recycle, a thermal spectrum system can be utilized, and an example is the molten salt reactor in which the fuel is continuously reprocessed on-line to remove unwanted elements (e.g. fission products), to recycle the heavy metals, and periodically introduce make-up fertile material. For whichever approach, as long as the nuclear system has a conversion ratio of about or greater than 1.0, the nuclear fuel cycle would be sustainable for a long time. These advanced systems can be used in a single-tier nuclear infrastructure or double-tier infrastructure. In all case, it is necessary that the last tier system be one with a conversion ratio of 1.0 or above.

The use of conventional LWRs or thermal-spectrum systems to extend resources has also been considered. The studies have shown that to achieve continuous recycle, enriched uranium support is required. In that case, low uranium utilization results. For this reason, concepts like the HTGR deep-burn, or the LWR MOX fuel cannot be used to increase the uranium utilization appreciably.

For each of the fuel cycle options in Tables 1 and 2 that indicate potential for significant improvement in fuel resource utilization (those shaded bright green in the Sustainability column), example fuel cycle technologies are provided below. These suggestions may not be the only technology combinations in that category, and may not be the only ones that might provide significant benefit, but are offered as representative of the category

- Once-through Critical - fast

- Uranium-based or thorium-based fast-spectrum breeder-burner (FMSR, CANDLE, SSFR)

- Once-through Subcritical - thermal

- $\quad$ U-based or Th-based externally-driven high or extreme burnup systems (LIFE)

- Once-through Subcritical - fast

- U-based or Th-based externally-driven high burnup systems (LIFE, ADS)

- U-based or Th-based externally-driven extreme burnup systems (LIFE)

- Recycle: Critical - thermal

- $\quad \mathrm{U} / \mathrm{Th} /{ }^{233} \mathrm{U}$ molten salt breeder

- $\quad$ LWBR Th ${ }^{233} \mathrm{U}$ with processing of all UNF

- Recycle: Critical - fast

- $\quad \mathrm{U} / \mathrm{Pu}$ fast breeder with processing of all UNF

- $\quad$ U/TRU fast breeder with processing of all UNF

- $\quad \mathrm{U} / \mathrm{Th} / 233 \mathrm{U}$ molten salt breeder

- $\quad$ Uranium-based or thorium-based fast-spectrum breeder-burner 
- Recycle: Critical - thermal and fast

- $\quad$ LWR / FR with actinide recycle and processing of all UNF

- $\quad$ HTGR / FR with actinide recycle and processing of all UNF

- Recycle: Subcritical - thermal

- Accelerator-driven system with actinide recycle and processing of all UNF

- Recycle: Subcritical - fast

- Accelerator-driven system with actinide recycle and processing of all UNF

- Breed and burn fast reactor / FR with actinide recycle and processing of all UNF

- Recycle: Subcritical - thermal and fast

- FFH or ADS with actinide recycle and processing of all UNF

- Recycle: Critical and Subcritical - thermal

- $\quad$ LWR / ADS with actinide recycle and processing of all UNF

- HTGR / ADS with actinide recycle and processing of all UNF

- Recycle: Critical and Subcritical - fast

- Breed \& Burn Reactor / ADS with actinide recycle and processing of all UNF

\section{Proliferation Risk and Security}

Proliferation risk is a "host state" issue, where the "adversary" of concern is an independent nation, and considers facility misuse and material diversion from civilian nuclear power facilities by the state, with the goal of developing and obtaining nuclear weapons. Timely detection of facility misuse or material diversion is the method used to deter such activities, and is the purpose of the existing nuclear safeguards and the international safeguards regime. The attractiveness of materials that could be recovered from the facilities, or from the source material in the facilities, affects the ability of attempts at proliferation to succeed. In reviewing both methodologies for assessing proliferation risk and studies where such assessments have been performed, it was apparent that assessments of proliferation risk are largely subjective in nature. As a consequence, the results of any evaluation of proliferation risk depend to a great extent on assumptions that are made about adversary capabilities and intent. It was also noted that country capabilities and intentions can and do evolve over time, such that an evaluation completed at one point in time may no longer be valid later, especially under a different set of circumstances with respect to underlying technical capabilities, security, or diplomatic motives and situations. Another factor was that transfer of certain technologies as part of a commercial fuel cycle may conveys technical capabilities to a state that could subsequently form the basis for clandestine facilities, even if a declared nuclear energy system was not misused. The observation has been that all of these considerations greatly complicate proliferation risk assessments and any conclusions that may be reached, to the point that no unambiguous distinction could be made on a technical basis between the various fuel cycle options, both once-through and recycle.

The security issue is a separate concern about either the theft of potentially weapons-usable materials from civilian facilities by a sub-national or terrorist group (the adversary) or the effects of sabotage. More recent studies of security risks appear to assume increasingly sophisticated capabilities of such groups, with the goals of a "nuclear explosive device", i.e., a nuclear weapon of uncertain performance, or other weapons using radioactive materials, such as radiation dispersal devices, (RDD). Prevention of theft, sabotage, and attack is the purpose of security, typically called physical protection, and the attractiveness of materials in the fuel cycle can be a relevant measure in this case. All nuclear fuel cycles contain potentially weapons-usable materials in one form or another, although some recycle fuel options may routinely handle more attractive products that would require less subsequent processing. As a result, 
the focus of the security issue is first on the types and quantities of SNM and other radioactive materials that would be vulnerable to theft, and second on limiting access to nuclear facilities. While distinctions between fuel cycle options can be observed based on the nature and characteristics of the materials in the fuel cycle, there was no obvious significant difference in the effect that this would have on the security issue and the ability to limit facility access, for either once-through or recycle.

\section{Safety}

Safety of an integrated nuclear fuel cycle includes all activities, although there is certainly a justified focus on reactor and processing facilities due to the concentrated radiological hazard and the potential for accidents to release radioactive materials to the biosphere. A larger view of safety includes issues related to obtaining the fuel resources, including mining and milling, uranium enrichment, and issues concerning used fuel, including handling, storage, transport, and disposal. However, all of these activities are closely regulated in the U.S., with licensing requirements for such activities. As such, by definition, all facilities and activities will have the required level of safety, and significant differences in safety between fuel cycle options have not been observed. However, this is not to say that the effort required to implement all nuclear fuel cycle options is the same, or that all technologies can be implemented to the same level of safety with the same amount of effort and cost. From the review of facilities and operations associated with the various nuclear fuel cycles and the technologies, there did not appear to be any option that was fundamentally unsafe. At the same time, there are some technology options that have more safety issues than others, with the expectation that additional expense would be incurred to ensure safe implementation of the technology. Similarly, when comparing fuel cycle options and all parts of the fuel cycle are considered, hazards from mining and milling are addressable by fuel cycle options that reduce the need for natural uranium or thorium. However, since such fuel cycle options typically involve recycle, the additional safety concerns for processing are added. With alternative nuclear fuel cycles, it appears that the safety risks can mainly be shifted from one part of the fuel cycle to another, and should be considered in evaluating the question of safety. Differences in the costs for achieving the required level of safety should be recognized, in that they can indirectly impact safety in the desire to lower the cost of the fuel cycle.

\section{Economics}

As discussed in Section 2.5, there are large costs associated with nuclear facilities with associated large uncertainties. The nominal costs for advanced recycle systems are shown to be slightly more expensive than those of a once through fuel cycle, but the difference is within the large uncertainties and are highly dependent upon non-technical considerations such as financing costs and construction duration. In many cases, the financing cost depends upon who is paying for the nuclear facility and taking the financial risk (e.g. government financed versus private financing). Therefore, there is substantial overlap in the costs of the fuel cycle facilities such that a well executed advanced recycle system could have a lower cost than a poorly executed once-through system. For these reasons, it was not possible to unambiguously determine that one fuel cycle option would have significantly different costs than another fuel cycle option in terms of real world costs.

With that said, there are a number of areas in which research and development can reduce the cost uncertainties as well as reduce the overall costs of all fuel cycle options. Small changes in these large costs imply significant financial impacts as the profitability of a nuclear enterprise is based on the balance of the large costs and the large revenues. Cost and uncertainty reductions of the nuclear fuel cycle can provide a significant incentive to support deployment of nuclear energy. While it is unlikely that there will be sufficient resources to reduce the cost uncertainties of all of the fuel cycle options to a level that can be used to differentiate options based on economics alone, there are a number of common features that can be applied across the options that can result in lower costs. These include: 
- Reduction of the complexity of the nuclear facilities being utilized. System complexity results in unanticipated costs during construction and operation, increases materials costs, and increases regulatory and licensing costs. All selected fuel cycle systems have potential for reduction in complexity based on optimization of design and operations to through $R \& D$ to reduce or remove nonessential functions and components.

- Increasing the operational efficiency of the nuclear facilities in terms of products per unit cost. For a reactor system, this means that systems with higher thermal efficiency can provide more electricity generation for nearly the same capital and operating costs. For fuel fabrication and processing facilities this primarily can be achieved through increasing the number of operational days per year.

- The financing costs and associated uncertainties can be reduced with nuclear facilities that have short construction durations without delays or schedule extensions. This is one primary reason for interest in Small Modular Reactors (SMR) that use advanced manufacturing approaches including factory fabrication. Nearly all of the fuel cycle concepts involve reactor systems that could be constructed as SMRs.

\subsection{Other Observations}

There are several other general observations about the integrated nuclear fuel cycles and technologies that apply to most, if not all, of the fuel cycles, including interim storage, processing, and technology complexity. These aspects can all affect not only the potential benefits that might be obtained, but may have economic implications.

Storage can be used as either a part of a fuel cycle, or as a means of providing time to develop and deploy an alternative fuel cycle. Interim storage, usually defined as longer term storage of several decades or more, can be used as part of the fuel cycle for several reasons, such as allowing the highly radioactive, short-lived fission products more time to decay. Initial storage of UNF is routinely done at reactors today, with LWR UNF cooling under water for decades in the spent fuel pool, prior to being moved into dry storage casks for what could be considered interim storage. Currently, storage is being considered for times up to 100 years, perhaps longer. Allowing for further decay of radionuclides in UNF lowers the radiation and decay heat, facilitating handling of the UNF. The decay can also mitigate issues related to the need to capture and store some of the gaseous fission products that are problematic for processing, such as ${ }^{85} \mathrm{Kr}$, since longer storage times greatly reduces the amounts of such shorter-lived materials. However, at the same time, the lower radiation will begin to increase the attractiveness of the UNF for diversion or theft. Depending on the relative importance of these two attributes, there may be an optimum or limiting time for disposition of the UNF, either processing for further use or for disposal.

There are other fuel cycle implications that accompany the use of storage in a fuel cycle, either favorable or unfavorable, depending on the specific characteristics of the fuel cycle. Some of the recyclable actinides have isotopes with radioactive decay half-lives on the order of a decade or so, meaning that during interim storage, these actinide isotopes will substantially decay into their decay products. One example is for the case of ${ }^{241} \mathrm{Pu}$, with a half-life of 14 years, and which decays into ${ }^{241} \mathrm{Am}$. The importance of this decay is that ${ }^{241} \mathrm{Pu}$ is a fissile isotope, and could be used to contribute to the fuel in the reactor. On the other hand, ${ }^{241} \mathrm{Am}$ complicates fabrication of recycle fuel in many cases, especially since it has sizeable decay heat and possibly unfavorable chemical attributes. As a result, the longer that UNF is in storage, the more ${ }^{241} \mathrm{Pu}$ decays into ${ }^{241} \mathrm{Am}$. For those fuel cycles that only recycle plutonium, such decay increases the amount of minor actinides going into the waste stream. This becomes an issue since ${ }^{241} \mathrm{Am}$ is the dominant decay heat contributor in UNF from about 60 years out to 1000 years, and if longer-term decay heat is an issue for the selected geologic disposal option, then the effect of allowing ${ }^{241} \mathrm{Pu}$ to decay into ${ }^{241} \mathrm{Am}$ may be detrimental to effectively using the repository, and in some cases may eliminate some deep geologic disposal options. 
At the same time, the curium isotopes are not only relatively short-lived, but have significant decay heat for the first few decades after UNF is discharged from the reactor. In this case, interim storage can be effectively used to almost eliminate the curium content. The lower radiation and decay heat can be beneficial to certain types of UNF processing, although other types are unaffected. The optimum time for processing UNF may depend on the intent of recycle, the capabilities of the separations technologies, and other factors. Some fuel cycle options propose processing at very short times after discharge, within two years, while other options can benefit from processing much older UNF. In other cases, it may not make any difference at all. The overall observation is that the change in composition of UNF during interim storage needs to be recognized when designing an integrated fuel cycle so that all of the corresponding effects are considered when evaluating nuclear fuel cycle options and technology choices. However, in considering an alternative fuel cycle for the future that includes recycle, the approach taken for processing older UNF does not have to be the same as that for the ongoing processing in the new fuel cycle.

Combinations of best options for each purpose can be used to create overall superior approaches, if that is what is desired.

The other issue concerns complexity of technology options which has been mentioned previously. The choice of a technology needs to be fully considered for the impact on all of the issues, even if the choice is being made for the benefit to one specific issue. Technology complexity may be required in many of the fuel cycle options as a result of the requirements for that fuel cycle, such as the specification of the elements in UNF to be separated in processing and recycled in reactors. Complexity usually comes with corresponding cost, and may also impact the ability of the processing to achieve the separations goals. However, when evaluating technologies for a specific purpose, a range of complexity is typically seen, and the technical maturity of the technology also enters the considerations. It is observed that choosing a fuel cycle or technology may not be a matter of choosing the simplest approach, but appears to be a choice of choosing the better fuel cycle options and corresponding technologies that best meet the objectives for the nuclear fuel cycle option within the desired time frame.

\section{SUMMARY}

This Options Study has been conducted for the purpose of providing information about the potential capabilities of nuclear fuel cycle options to address the current issues associated with nuclear power. To the extent possible, this study made a comprehensive examination of all possible nuclear fuel cycle options and technologies, unrestricted by any limitations of economics, technical readiness, current technical viability, past or current policies, or speculated future conditions. The information used in the study was obtained from available literature, studies, analyses, and data, all evaluated on a consistent basis. The intent was to conduct an unbiased technical assessment of the capabilities of nuclear fuel cycle options.

Depending on which issue or issues are of highest importance, this information can be used to inform decisions about productive directions for R\&D. The recently-issued DOE roadmap had 4 top level R\&D Objectives, as follows:[40]

1. Develop technologies and other solutions that can improve the reliability, sustain the safety, and extend the life of current reactors

2. Develop improvements in the affordability of new reactors to enable nuclear energy to help meet the administration's energy security and climate change goals

3. Develop sustainable nuclear fuel cycles

4. Understand and minimize the risks of nuclear proliferation and terrorism

The summary observations from this Options Study provide information on what issues are addressable with a nuclear fuel cycle option, and the extent to which the issues can be affected. For this purpose, the 
study focused on only identifying those fuel cycle options that were able to make a "significant difference," i.e., potential performance is clearly greater than the uncertainties, usually resulting in improvements of an order of magnitude or more for most of the measures described in the Phase I report.

With respect to the R\&D Objective of sustainability, it appears that nuclear waste management may only be improved mainly with nuclear fuel cycle options using recycle, since processing can be used to improve the characteristics of wastes requiring deep geologic disposal and reduce the radiological risk from UNF, providing for more efficient use of deep geologic disposal facilities and enabling other deep geologic disposal options. Once-through fuel cycle options are limited in this respect since disposal of $\mathrm{UNF}$ is always required. One exception may be the use of externally-driven irradiation systems to achieve complete consumption of the fuel.

It is clear that alternative nuclear fuel cycles can contribute to developing sustainable nuclear fuel cycles by increasing the utilization of fuel resources, which reduces the environmental impact related to obtaining the fuel resource and increases self-sufficiency of the fuel resources. Results of the reviews performed in the Options Study show that while this is possible to some extent with a few once-through fuel cycle options using externally-driven irradiation systems, recycle options can develop this potential to a much greater extent, and for a wider range of technology options.

For the other issues, the situation was not so clearly distinguishable. The reviews indicated that while alternative nuclear fuel cycles and technologies may not have any significant difference in proliferation risk based on the technical aspects related to the materials and products, some options may assist in reducing the risks from proliferation and terrorism by using fuel cycles and technologies that allow effective and efficient implementation of nuclear safeguards, by enabling security at nuclear fuel cycle facilities, and by reducing the attractiveness of readily-available materials. Also, there did not seem to be any discrimination in the level of safety that resulted from the choice of the fuel cycle option since all fuel cycle facilities including reactors are strictly licensed and regulated for safety. However, it was also noted that some technologies had additional safety-related risks that would require more design features for prevention and mitigation measures, where achieving the required level of safety may have negative economic impacts. From an economics point of view, review of previous studies and estimates resulted in the observation that the overall economics for an alternative fuel cycle did not appear result in a change that was clearly larger than the uncertainties, i.e., even though there were differences in the estimated mean cost for various fuel cycle options, these differences were well within the overlapping uncertainty distributions for each of the estimates. As a result, it was observed that alternative fuel cycles may be considered without necessarily incurring significantly different overall costs, although there can be significant variations between technology options within a fuel cycle. It should be noted for these three issues that although it was not possible to clearly identify fuel cycle options that could provided a significant benefit for a variety of reasons, proliferation risk and security (high level of subjectivity), safety (regulation requires all systems to be safe), and economics (uncertainties are larger than the differences), this is not necessarily a negative result since the lack of distinction between fuel cycle options may be contrary to prevailing perceptions. These observations allow consideration of all fuel cycle options on a more or less equal basis with respect to these issues, enabling a wide range of options.

\subsection{Options Requirements}

Based on the above, of the five major issues with nuclear power, only two, nuclear waste management and sustainability are clearly amenable to significant improvements by using an alternative nuclear fuel cycle. In most cases it should be noted that recycle is necessary to achieve a significant beneficial effect, although only certain recycle approaches will provide such benefit. The following sections summarize the requirements for a fuel cycle option to have a significant beneficial impact. 


\section{Nuclear Waste Management}

Achieving significant benefits to nuclear waste management involves addressing deep geologic disposal, LLW disposal, and storage needs. Regarding deep geologic disposal, it was observed that the isolation performance of each combined engineered repository and geologic environment was not the same, with some being more sensitive to actinide elements as compared to fission products, and some being more sensitive to disturbances to the repository than others. With respect to disturbances, it appeared that the risk from disposal may be reduced by reducing the actinide inventory in the repository to reduce both actinide elements and their decay products (an action important for either uranium or thorium use), although in some cases it would be beneficial to reduce the inventory of certain fission products as well. While this could be accomplished by reducing the planned capacity of a repository, either complete consumption of the fuel or recycle of the actinide elements was seen to provide a significant benefit. However, it was also observed that there is subjectivity to the analysis of disturbed events, especially for the assumptions made as to the nature and consequences of the disturbance, and uncertainty is high for predicting future events. Reduction in inventory lessens the importance of these uncertainties in an overall assessment of the repository capabilities.

The situation is more complex for the undisturbed performance of the repository. Some repositories may not have releases for such conditions, but achieving this may be difficult in practice and may require substantial reductions in the decay heat of the emplaced materials to enable such disposal. For the first few decades, decay heat is dominated by short-lived fission products, and this could be addressed by using interim storage prior to disposal. However, the longer-term decay heat, out to two thousand years or more, resulting from some of the actinide elements can only be addressed by recycle to keep these elements out of the wastes, aside from minor processing losses, or by distributing the waste over larger emplacement areas, which might also require fuel separation to reduce actinide concentrations to levels below that of intact UNF. Other repositories are estimated to have very small losses for undisturbed conditions, with some preferentially releasing actinide elements and other releasing fission products. For repositories sensitive to actinide elements, recycle can have a significant impact on such releases. However, recycle does not appear to be effective for those sensitive to fission products, since most fission products are not amenable to recycle. It was observed that analysis of undisturbed performance may also be partly subjective due to assumptions that are made, but in general there appeared to be less uncertainty about performance for undisturbed conditions.

Overall, for a nuclear fuel cycle option to reduce the risk from deep geologic disposal, actinide recycle appears to benefit disturbed performance for all repositories, and undisturbed performance for some repositories. Actinide recycle may also enable disposal in some types of repositories by reducing longterm decay heat. Very few fission products are amenable to recycle, so fission product recycle may have limited benefit.

\section{Sustainability}

Achieving significant benefits to sustainability requires reduction in natural resource requirements and limiting environmental impacts. Reducing the need for fuel resources requires more complete utilization of the fuel resource. This can only be accomplished by more efficient internal breeding from fertile materials, such as converting ${ }^{238} \mathrm{U}$ to ${ }^{239} \mathrm{Pu}$ or ${ }^{232} \mathrm{Th}$ to ${ }^{233} \mathrm{U}$. This may be achievable with some oncethrough and recycle fuel cycles, although it is more difficult to do with once-through approaches and the eventual utilization will be lower. Certain technologies are more suitable for higher breeding, typically using fast neutrons, although breeding can be obtained with thermal neutrons using $\mathrm{Th} /{ }^{233} \mathrm{U}$ fuel.

Sustainability also requires sufficient natural resources for waste disposal, for both deep geologic disposal and LLW. The repository space needed for disposal is a decay heat issue, and can be addressed by reducing the decay heat of the emplaced materials. Again, for the first few decades, decay heat is 
dominated by fission products, and this could be addressed by using interim storage prior to disposal. However, the longer-term decay heat, out to two thousand years or more, resulting from some of the actinide elements can only be addressed by recycle to keep these elements out of the wastes, aside from minor processing losses. As a result, once-through fuel cycles are limited in their ability to extend resources for deep geologic disposal due to the disposal of UNF, although cases with complete consumption of the fuel may be beneficial. Recycle of actinides without disposal of UNF can provide significant increases in use of repository space.

Table 3. Summary Observations on Fuel Cycle Option Capabilities

\begin{tabular}{|c|c|c|}
\hline Nuclear Power Issue & $\begin{array}{l}\text { Nuclear Fuel Cycle Option Requirements to } \\
\text { Provide Significant Benefits }\end{array}$ & $\begin{array}{l}\text { Suitable Nuclear Fuel Cycle } \\
\text { Options }\end{array}$ \\
\hline Nuclear Waste Management & $\begin{array}{l}\text { - Reduce actinide and decay product content in } \\
\text { UNF and wastes requiring geologic disposal: } \\
\text { - Complete consumption of fuel } \\
\text { - Actinide recycle } \\
\text { - Reduce decay heat of UNF and wastes for } \\
\text { disposal in some geologic environments. } \\
\text { - Limit LLW generation. }\end{array}$ & $\begin{array}{l}\text { - Recycle options with } \\
\text { actinide recycle and no UNF } \\
\text { disposal. } \\
\text { - Externally-driven once- } \\
\text { through with complete fuel } \\
\text { consumption. }\end{array}$ \\
\hline Proliferation Risk and Security & $\begin{array}{l}\text { - Fuel cycles and technologies that enable } \\
\text { effective and efficient safeguards } \\
\text { implementation, including: } \\
\text { - Use of existing safeguards technologies } \\
\text { - Best practices } \\
\text { - Fuel cycles that allow effective security and } \\
\text { materials with lower attractiveness. }\end{array}$ & $\begin{array}{l}\text { - All fuel cycle options using } \\
\text { "safeguards-friendly" } \\
\text { technologies. } \\
\text { - Fuel cycles with lower } \\
\text { material attractiveness for } \\
\text { SNM in UNF and products. }\end{array}$ \\
\hline Safety & $\begin{array}{l}\text { - Use technologies with no irresolvable safety } \\
\text { vulnerabilities. }\end{array}$ & $\begin{array}{l}\text { - Virtually all fuel cycle } \\
\text { options and technologies. }\end{array}$ \\
\hline Sustainability & $\begin{array}{l}\text { - Increase internal conversion of fertile materials } \\
\text { to fissile materials, i.e. "breeding" to improve } \\
\text { fuel utilization and reduce environmental impact. } \\
\text { - Reduce decay heat of UNF and wastes going to } \\
\text { deep geologic disposal to reduce repository space } \\
\text { requirements. }\end{array}$ & $\begin{array}{l}\text { - Once-through and recycle } \\
\text { fuel cycles with more } \\
\text { efficient breeding than } \\
\text { LWRs. } \\
\text { - Recycle fuel cycles with } \\
\text { actinide recycle and no UNF } \\
\text { disposal. }\end{array}$ \\
\hline Economics & $\begin{array}{l}\text { - Avoid unnecessary increases in complexity. } \\
\text { - Avoid systems with larger waste generation, } \\
\text { extreme technical requirements or inherent safety } \\
\text { or security vulnerabilities requiring additional } \\
\text { design features, or requiring rare resources. }\end{array}$ & $\begin{array}{l}\text { - All fuel cycle options but } \\
\text { less complex technologies } \\
\text { may have fewer issues with } \\
\text { costs. }\end{array}$ \\
\hline
\end{tabular}

\subsection{R\&D Needs and Decisions}

From the review of nuclear fuel cycle options that can potentially provide significant benefits to the issues associated with nuclear power, it is apparent that some of the possibilities are more well-developed, having been the subject of research for several decades in some cases since some of the issues are decades old. Other possibilities are quite immature, and would require substantial investment in time and funding (and in some cases a number of revolutionary technical developments) to bring them to a level of maturity sufficient to evaluate their suitability for further development and potential implementation.

Consequently, the R\&D needs cover a wide range of possibilities. Since the goals for each issue can be accomplished with numerous specific solutions, it would appear that the selections from the set of specific options would be more a matter of preference rather than one of fundamental technical difference, although this needs to be further investigated. As a result, the required R\&D to address an issue also 
covers a wide range, from solutions that are barely at proof-of-principle to those that are at the pilot-scale demonstration phase.

Given the range of potential solutions for each issue, and the implications for $\mathrm{R} \& \mathrm{D}$, it would seem that decisions need to be made first on what the nuclear fuel cycle option would be asked to do. The Options Study provides an overview of what is possible and what may not be possible, along with the cautions about the level of subjectivity that exists for some of the issues.

\subsection{Next Steps}

The Options Study has reviewed numerous past studies on nuclear fuel cycles, specific fuel cycle approaches, and individual aspects of the fuel cycle, with the purpose of evaluating the possibilities of nuclear fuel cycle options to significantly benefit the current issues associated with the use of nuclear power. The issues have been analyzed to provide the underlying reasons for the issues and to develop requirements for an alternative fuel cycle. For each issue, information about connections between specific fuel cycle options and the nuclear power issues identifies whether significantly beneficial approaches fundamentally exist, and if so, what they are. Issues where no options apparently exist for significant beneficial improvement are also discussed, providing the reasons why options do not appear to exist at this time. For those issues that can have significant beneficial improvement, examples of existing or proposed options are provided for perspective on the extent to which technologies may be available to address the issues, and where additional R\&D would be required.

Moving forward, more detailed examination of those options that have the potential to address the issues with nuclear power appears warranted. It is quite clear that the approach taken in the Options Study of considering the entire nuclear fuel cycle as an integrated entity is absolutely essential for developing an effective nuclear fuel cycle, from mining to disposal, since many of the aspects of each activity are so closely interrelated and affect the issues with nuclear power.

\section{REFERENCES}

1. R. Wigeland, T. Taiwo, M. Todosow, W. Halsey, and J. Gehin, “AFCI Options Study,” AFCI-TIOPMO-MI-DV-2009-000086, September 30, 2009

2. U.S. DOE, Department of Nuclear Energy, "Draft Global Nuclear Energy Partnership Programmatic Environmental Impact Statement," DOE/EIS-0396, October 2008

3. The Nuclear Waste Policy Act of 1982 (Public Law 97-425) L. J. Carter, Nuclear Imperatives and Public Trust: Dealing with Radioactive Waste (Resources for the Future, Washington, D.C., 1987).

4. U.S. Environmental Protection Agency (EPA), "Background Information Document Final Rule for High- Level and Transuranic Radioactive Wastes," EPA 52011-85-023 (EPA, Office of Radiation Programs, Washington, D.C., 1985)

5. R. Rechard, "Historical Relationship Between Performance Assessment for Radioactive Waste Disposal and Other Types of Risk Assessment," Risk Analysis, Vol. 19, No. 5, 1999

6. H. Behnsen, "Underground Repositories for Chemically Toxic Waste in German Salt and Potash Mines," Reviews in Engineering Geology, 19, p. 31, 2008

7. European Commission, Brussels, "Requirements for Facilities and Acceptance Criteria for the Disposal of Metallic Mercury," BiPRO GmbH, Final Report, 07.0307/2009/530302, April 2010

8. P. Brady, et al, "Deep Borehole Disposal of High Level Radioactive Waste," Sandia National Laboratories, SAND2009-4401, August 2009

9. "Red Impact - Impact of Partitioning, Transmutation, and Waste Reduction Technologies on the Final Nuclear Waste Disposal - Synthesis Report," Forschungszentrum Jülich, GmbH, FP6 Contract No: F16W-CT-2004-002408, September 2007 
10. U.S. DOE, Office of Civilian Radioactive Waste Management, "Total System Performance Assessment Model/Analysis for the License Application”, MDL-WIS-PA-000005 Rev 00, January 2008

11. R.A. Wigeland, T.H. Bauer, T.H. Fanning, and E.E. Morris, "Separations and Transmutation Criteria to Improve Utilization of a Geologic Repository," Nuclear Technology, Vol. 154, No. 1, April 2006

12. National Academy of Sciences/National Research Council (NAWNRC), "The Disposal of Radioactive Waste on Land: Report of the Committee on Waste Disposal of the Division of Earth Sciences," Publication 519 (NASINRC, Washington, D.C., 1957)

13. W. C. McClain and R. L. Bradshaw, "Status of Investigations of Salt Formations for Disposal of Highly Radioactive Power- Reactor Wastes," Nucl. Saf 11(2), 130-141 (1970)

14. Waste Isolation Pilot Plant, http://www.wipp.energy.gov

15. P.N. Swift, et al, "Broader Perspectives on the Yucca Mountain Performance Assessment," $12^{\text {th }}$ International High-Level Radioactive Waste Management Conference, Las Vegas, Nevada, September 2008

16. International Atomic Energy Agency, Proliferation Resistance Fundamentals for Future Nuclear Energy Systems, Safeguards Technical Reports No. 332, IAEA, Vienna (2002)

17. U.S. DOE, National Nuclear Security Administration, "Draft Nonproliferation Impact Assessment for the Global Nuclear Energy Partnership Programmatic Alternatives," (December 2008).

18. American Physical Society, "Nuclear Power and Proliferation Resistance: Securing Benefits, Limiting Risk," (May 2005)

19. Nuclear Energy Research Advisory Committee, "Technological Opportunities to Increase the Proliferation Resistance of Global Civilian Nuclear Power Systems," (January 2001)

20. U.S. DOE, "Nuclear Proliferation and Civilian Nuclear Power: Report of the Nonproliferation Alternative System Assessment Program (NASAP)," (June 1980)

21. Generation IV International Forum, Proliferation Resistance \&Physical Protection Evaluation Methodology Expert Group, "Evaluation Methodology for Proliferation Resistance and Physical Protection of Generation IV Nuclear Energy Systems," Revision 5, GIF/PRPPWG/2006/005 (November 2006)

22. IAEA, "Guidance for the Application of an Assessment Methodology for Innovative Nuclear Energy Systems, INPRO Manual - Overview of the Metholodogy," IAEA-TECDOC-1575 Rev. 1 (November 2008)

23. Bari, R., et al.: Proliferation Resistance and Physical Protection Evaluation Methodology Development and Applications, BNL-90259-2009-CP; presentation to the GIF Symposium, Paris, France, September $9-10,2009$

24. U.S. DOE, National Nuclear Security Administration, "Draft Nonproliferation Impact Assessment for the Global Nuclear Energy Partnership Programmatic Alternatives,“ (December 2008)

25. Charles G. Bathke, et al., "An Assessment of the Attractiveness of Material Associated with a MOX Fuel Cycle from a Safeguards Perspective," Proceedings of INMM 50th Annual Meeting, July 12-16, 2009, Tucson, Arizona

26. C. Bathke, et al., "The Attractiveness of Materials in Advanced Nuclear Fuel Cycles for Various Proliferation and Theft Scenarios," Proceedings of Global 2009, September 6-11, 2009, Paris, France

27. B. Sleaford, et al., "Nuclear Material Attractiveness: An Assessment of Material from PHWRs in a Closed Thorium Fuel Cycle," Proceedings of European Nuclear Conference 2010, May 30-June 2, 2010, Barcelona, Spain

28. International Atomic Energy Agency, Guidance for the Application of an Assessment Methodology for Innovative Nuclear Energy Systems, INPRO Manual - Physical Protection, Volume 6 of the Final Report of Phase 1 of the International Project on Innovative Nuclear Reactors and Fuel Cycles (INPRO), IAEA-TECDOC-1575, Vienna (2007)

29. Organization for Economic Co-operation and Development - International Atomic Energy Agency, "Uranium 2009: Resources, Production, and Demand," OECD Paris, 2010

30. U.S. Energy Information Administration, http://www.eia.doe.gov/cneaf/nuclear/umar/umar.html 
31. J.R. Engel, et al, "Molten-Salt Reactors for Efficient Nuclear Fuel Utilization Without Plutonium Separation," Oak Ridge National Laboratory, ORNL/TM-6413

32. R.C. Robertson, et al., Conceptual Design Study of a Single-Fluid Molten-Salt Breeder Reactor, Oak Ridge National Laboratory, ORNL-4541 (1971)

33. D. R. Connors, S. Milani, J. A. Fest, R. Atherton, Design of the Shippingport Light Water Breeder Reactor, WAPD-TM-1208 Special External Distribution, Bettis Atomic Power Laboratory, January 1979

34. AREVA News Release, "AREVA Accepts Conditional Commitment for DOE Loan Guarantee for Eagle Rock Facility”, July 7, 2010

35. DOE News Release, "DOE Offers Conditional Loan Guarantee for Front End Fuel Cycle Facility in Idaho," May 20, 2010

36. U.S. Energy Information Administration, "Electric Power Monthly with data for June 2010," September 10, 2010 Edition

37. Analysis of the Total System Life-Cycle Cost of the Civilian Radioative Waste Management Program, U.S. Department of Energy, Office of Civilian Radioactive Waste Management, Washington, DC, July 2008

38. D. Shropshire, et al, “Advanced Fuel Cycle Cost Basis," Idaho National Laboratory, INL/EXT-0712107, December 2009

39. Dynamic Systems Analysis Report for Nuclear Fuel Recycle, GNEP-SYSA-AI-SS-RT-2008-000264, May 31, 2008

40. U.S. DOE, Office of Nuclear Energy, "Nuclear Energy Research and Development Roadmap Report to Congress," April 2010 